Running head: HOW CHEATING UNDERMINES THE PERCEIVED VALUE OF JUSTICE

How Cheating Undermines the Perceived Value of Justice in the Workplace:

The Mediating Effect of Shame

Annika Hillebrandt

Ryerson University

Laurie J. Barclay

Wilfrid Laurier University

Annika Hillebrandt, Ted Rogers School of Management, Ryerson University; Laurie J. Barclay, Lazaridis School of Business and Economics, Wilfrid Laurier University.

An early version of this article was presented at the Academy of Management conference, Atlanta, GA, August 2017. This research was supported by grants from the Social Sciences and Humanities Research Council of Canada awarded to Annika Hillebrandt (No. 7672012-1730) and Laurie J. Barclay (No. 435-2016-1477) as well as an Ontario Graduate Scholarship awarded to Annika Hillebrandt. We thank Anja Krstic and Teodora Makaji for their help with the data collection and Marie Mitchell and Sara Murphy for their helpful comments on previous versions of this manuscript.

Correspondence concerning this article should be addressed to Annika Hillebrandt. Ted Rogers School of Management, Ryerson University, 55 Dundas Street West, Toronto, Ontario, M5G 2C3, Canada. Email: ahillebrandt@ryerson.ca.

(C) 2020, American Psychological Association. This paper is not the copy of record and may not exactly replicate the final, authoritative version of the article. Please do not copy or cite without authors' permission. The final article will be available, upon publication, via its DOI: $10.1037 /$ apl0000485 


\begin{abstract}
Scholars have devoted significant attention to investigating when and why people cheat in organizations. However, there is increasing recognition that these behaviors can be difficult to eradicate, which points to the importance of understanding the consequences of cheating. Given that cheating violates moral norms that govern social relationships, it is critical to understand how cheating can influence social dynamics in the workplace. Drawing upon appraisal theories, we argue that cheating can have damaging consequences for individuals and their social relationships by eliciting shame. In turn, shame can reduce the extent to which individuals value receiving justice - a critical facilitator of social relationships in the workplace. We test our predictions across six studies using different samples and methodologies. In Study 1, we find that cheating is negatively associated with the importance people place on others upholding justice for them (i.e., overall justice values). In Studies 2-6, we demonstrate that shame plays a mediating role in this relationship, even in the presence of guilt and embarrassment. In Studies 35, we identify organizational identification as a moderator and show that the effect of cheating on shame is stronger for those with high (versus low) identification. Theoretical implications include the importance of identifying the outcomes of cheating for individuals within organizational contexts, understanding the functional and dysfunctional consequences of shame, recognizing the differential effects of discrete emotions, and elucidating the role of identity within the context of cheating. We conclude with practical recommendations for managing cheating behaviors and their outcomes in the workplace.
\end{abstract}

Keywords: cheating, behavioral ethics, justice, shame, organizational identification 


\section{How Cheating Undermines the Perceived Value of Justice in the Workplace: The Mediating Effect of Shame}

When people cheat in any arena, they diminish themselves. - Cheryl Hughes

From showing up to work late and taking unwarranted sick days to overstating performance and inflating expense reports, cheating behaviors are extremely common in the workplace (Mitchell, Baer, Ambrose, Folger, \& Palmer, 2018). Indeed, scholars have noted that "everybody has the capacity to be dishonest, and almost everybody cheats" (Ariely, 2012, p. C1). Whereas past research has focused on when and why workplace cheating behaviors emerge (Mitchell et al., 2018), there is also recognition that cheating behaviors may be especially difficult to eradicate precisely because they tend to be committed by "ordinary" people who generally value morality (Shalvi, Gino, Barkan, \& Ayal, 2015, p. 125). Thus, it is also critical to understand the consequences of cheating for individuals. Given that cheating involves an attempt to create advantages or benefits for oneself by violating moral norms that govern social relationships (e.g., Mitchell et al., 2018; Shu, Gino, \& Bazerman, 2011), we examine the outcomes of workplace cheating behavior on a critical facilitator of social relationships in the workplace - organizational justice (Cropanzano, Bowen, \& Gilliland, 2007).

Drawing upon appraisal theories of emotions (e.g., Lazarus, 1991), our general argument is that engaging in cheating behavior can have damaging consequences for individuals and their social relationships by reducing the extent to which individuals value justice. More precisely, we propose that individuals who have cheated may place less value on others upholding justice for them (i.e., overall justice values; cf. Holtz \& Harold, 2013) because they perceive themselves as less worthy of social rewards and seek to compensate for having violated moral norms that are important to the group. Further, we propose that these effects are mediated by shame - a moral 
emotion that involves feeling inferior to others and is associated with motivations to withdraw (e.g., Tangney, Miller, Flicker, \& Barlow, 1996). We also examine organizational identification as a theoretically relevant boundary condition. Figure 1 displays our theoretical model.

Our goal is to enhance our theoretical understanding of how cheating impacts individuals within organizations in three ways. First, scholarly attention has focused on why cheating emerges, whereas the consequences of this behavior have received less attention (Moore \& Gino, 2015). Moreover, studies that have examined the aftermath of cheating often emphasize how people try to neutralize the effects of cheating by justifying, rationalizing, or distancing themselves from the behavior (Shu et al., 2011). However, given that cheating involves a violation of moral and social norms, we argue that it can also impact how people subsequently navigate their social environments. By examining how cheating influences people's emotions (e.g., shame) and the extent to which they value receiving fair treatment (i.e., overall justice values), we answer calls in the literature to broaden our understanding of the intrapersonal and interpersonal implications of cheating in organizational settings (e.g., Moore \& Gino, 2015). Further, by focusing on overall justice values, we examine a critical social facilitator that has been associated with a broad range of important employee and organizational outcomes (e.g., Colquitt et al., 2013). We also answer longstanding calls for empirical studies that contribute to a closer integration of the behavioral ethics and organizational justice literatures (e.g., Cropanzano \& Stein, 2009; Schminke, Ambrose, \& Noel, 1997).

Second, we contribute to the understanding of shame - a powerful emotion that can have significant consequences not only for individuals but also for their social relationships (Tangney, 1995). While shame may prompt positive behaviors (e.g., exemplification behaviors that may make one appear dedicated; Bonner, Greenbaum, \& Quade, 2017), we argue that shame can also 
negatively impact social dynamics by reducing the value that people place on justice. Further, we distinguish the effects of shame from related emotions (i.e., guilt and embarrassment) thereby enhancing our understanding of disparate discrete emotions within the context of cheating.

Third, shame is experienced when one's core self is called into question (e.g., following a violation of moral or social norms; Lewis, 1971). Given this close association between shame and identity, we argue that it is critical to understand how one's social identity - the part of one's self-concept that is derived from perceived group membership (e.g., Tajfel, 1978) - can influence the relationship between cheating and shame. We examine organizational identification - a specific form of social identification whereby individuals derive a part of their identity from their association with their organization (Ashforth \& Mael, 1989). We propose that the relationship between cheating and shame will be stronger when organizational identification is high (versus low). By examining a theoretically relevant boundary condition, we deepen our understanding of how individuals are affected by cheating within organizational settings.

Taken together, our overall goal is to examine how cheating behavior can influence individuals and their social relationships through its effects on shame and organizational justice thereby providing insight into the consequences of cheating for individuals and organizations.

\section{Theoretical Background}

Workplace cheating behavior has been defined as "unethical acts that are intended to create an unfair advantage or help attain benefits that an employee would not otherwise be entitled to receive" (Mitchell et al., 2018, p. 54). Workplace cheating is considered an unethical behavior because it is an intentional behavior that violates shared moral standards. Moreover, cheating is a self-interested behavior and individuals may fail to consider the consequences of their cheating behavior for others while pursuing their own interests (for reviews, see Gino, 
2015; Moore \& Gino, 2013). This definition distinguishes workplace cheating behavior from other forms of unethical workplace behavior that are not motivated by self-interest, such as unethical pro-organizational behavior, which is intended to benefit others (e.g., Umphress \& Bingham, 2011), or deviant behaviors such as sabotage and vandalism, which may be driven by a motivation to harm another entity rather than to benefit oneself (e.g., Jones, 2009).

By violating moral standards in pursuit of one's own self-interest, cheating runs counter to the widely held norms of cooperation and altruism that underlie social relationships (de Waal, 2006). As such, cheating can create a tension between one's desires for personal benefits (i.e., satisfying self-interests) versus maintaining supportive relationships and viewing oneself as a moral person (e.g., Aquino \& Reed, 2002). This raises the question of how individuals who have cheated may resolve this discrepancy. Our general argument is that individuals who have cheated will adjust their values to match their behaviors. In particular, we propose that individuals who have cheated may place less value on organizational justice - an important social reward that is also a critical facilitator of workplace relationships.

\section{Cheating and Overall Justice Values}

Scholars have long recognized the importance of justice for the functioning of social relationships in organizations (Cropanzano et al., 2007). Employees care about justice because it can fulfill critical psychological needs and communicate information about the quality of one's social relationships - receiving justice can enhance one's sense of self-worth and belongingness by signaling that one is a valued and respected member of one's organization (e.g., Lind \& Tyler, 1988). Organizations often care about justice because it is associated with a broad range of employee and organizational outcomes (see Colquitt et al, 2013) and serves important roles in the organization (e.g., employees' negative reactions to perceived unfairness can serve as a social 
control on leaders' behaviors; Oç, Bashshur, \& Moore, 2015). Thus, justice is important not only for individuals and organizations but also for the effective functioning of social relationships - it is 'the 'glue' that allows people to work together effectively [and] defines the very essence of individuals' relationships to employers"'(Cropanzano et al., 2007, p. 34).

However, individuals must value justice for it to facilitate social relationships. Given that justice can satisfy important psychological needs (e.g., Lind \& Tyler, 1988), one might expect that individuals should always prefer relatively high levels of justice and be quite sensitive to the failure to uphold justice. However, the preference for justice is not universal - employees prefer treatment that confirms their self-views (i.e., the thoughts and feelings they hold about themselves), such that those who feel less worthy of respect may fail to show a preference for fair treatment; that is, they may value justice less (e.g., Wiesenfeld, Swann, Brockner, \& Bartel, 2007). Taken together, the extent to which individuals value justice may be influenced by their underlying motivations (Barclay, Bashshur, \& Fortin, 2017).

We propose that cheating can influence the extent to which individuals value receiving justice. Given that cheating is self-interested behavior that violates moral norms governing social interactions within the group (Shu et al., 2011), we argue that people who have cheated may question whether their standing in the group is warranted and feel motivated to align their preferences for justice with their behavior. That is, given that justice is an important social reward that can communicate self-worth and a sense of standing ( Lind \& Tyler, 1988), people may place less value on justice after cheating as a way to compensate for violating the norms that govern group behavior (i.e., to reduce inconsistency between their behaviors and values).

Hypothesis 1: Cheating is negatively associated with overall justice values.

Given our focus on the consequences of cheating for individuals, we examine self- 
referencing justice values (i.e., the extent to which individuals personally value receiving justice from others rather than the extent to which they value justice in general). Further, we focus on overall justice rather than the specific justice dimensions because overall justice is a holistic judgment that provides a more complete and accurate depiction of employees' actual justice experiences, is more proximal to downstream reactions, and reflects a more parsimonious approach (e.g., Ambrose \& Schminke, 2009; Lind, 2001; Törnblom \& Vermunt, 1999).

\section{The Mediating Role of Shame}

Drawing upon appraisal theories of emotion (e.g., Lazarus, 1991), we propose that shame - a moral self-conscious emotion - can serve a mediating role in the relationship between cheating and overall justice values. Moral emotions (e.g., shame, guilt) provide feedback on one's behaviors, serving as "moral barometers" that reflect one's evaluation of the morality of a behavior (e.g., the propriety of the behavior) and how the behavior reflects the self (e.g., one's character or worth) (e.g., Lazarus, 1991; Tangney, Stuewig, \& Mashek, 2007). When people experience negative moral emotions (e.g., shame), the instigating behaviors should be less rewarding and people will be less likely to engage in these behaviors in the future (Tangney et al., 2007). That is, moral emotions can either punish or reinforce the behavior by providing immediate feedback about the appropriateness of the behavior.

We argue that cheating is likely to be relevant for shame because it is an intentional and self-interested unethical behavior that is intended to advance one's own interests (Mitchell et al., 2018). Whereas pro-organizational unethical behaviors may be justified as being necessary to help others (e.g., Umphress \& Bingham, 2011) and deviant behaviors may be justified as being needed to re-establish social norms (e.g., when individuals take revenge to show that another's behavior will not be tolerated; Tripp \& Bies, 1997), the primary purpose of cheating is to pursue 
one's own interests. This should make it more difficult for people to rationalize or justify these behaviors. Further, cheating may be seen as being more reflective of their personal identity since they are voluntarily choosing to engage in this unethical behavior for their own interests. We argue that these features of cheating make it particularly susceptible to the experience of shame.

Within the context of cheating, shame can focus attention on the self as people assess what the behavior means for them, their identity, and their social relationships (e.g., whether the behavior is congruent with who they are and who they want to be; Tracy \& Robins, 2007). Given that cheating violates moral standards and rules (Shu et al., 2011), this behavior tends to be incongruent with one's goals to be viewed as a moral and cooperative person. Moreover, given that the self is responsible for these violations, cheating can threaten one's identity as a moral person and spark concerns about evaluations from others. These appraisals of goal incongruence and self-blame for moral violations are closely associated with shame (Tracy \& Robins, 2006).

Hypothesis 2: Cheating is positively associated with shame.

Shame involves feeling diminished and inferior to others (e.g., Scherer \& Wallbott, 1994) and is associated with behavioral motivations to hide and withdraw from others (e.g., Tangney et al., 1996). Moreover, individuals who feel ashamed can attempt to affirm shared and personal moral values by punishing themselves for their moral transgressions (Griffin et al., 2016). As such, experiencing shame may have implications that extend beyond individuals to also impact their social relationships. By negatively impacting one's self-views (i.e., by eliciting shame), we propose that cheating can diminish the value that people place on others upholding justice for them. That is, we hypothesize that shame is negatively associated with overall justice values and serves as a mediator in the relationship between cheating and overall justice values.

Hypothesis 3: Shame is negatively associated with overall justice values. 
Hypothesis 4: Shame mediates the negative effect of cheating on overall justice values.

\section{The Moderating Role of Organizational Identification}

Shame is directed at one's core self - it is an emotion that is experienced when one's identity is called into question following the violation of a moral or social norm (Lewis, 1971; Tangney et al., 1996). Given this close relationship between shame and identity, we argue that it is critical to understand how the relationship between cheating and shame can be influenced by one's social identity - the part of one's self-concept that is derived from perceived membership in a group (Tajfel, 1978). Specifically, people not only define themselves in terms of individual characteristics that differentiate them from other people, but also as members of social categories (Tajfel \& Turner, 1985). Given our focus on workplace cheating behavior, we examine organizational identification - a form of social identification whereby the individual derives a part of their identity from their association with their organization (Ashforth \& Mael, 1989).

We propose that organizational identification can impact the relationship between cheating and shame, for several reasons. First, a central implication of social identity is that one's behavior is not only evaluated against personal standards, but also according to how the behavior may impact the group (Tajfel, 1978; Tajfel \& Turner, 1985). Thus, people who more strongly identify with their organization should be more likely to consider the implications of their behavior for their organization. Given that cheating involves a "singular focus" on one's own interests at the expense of others (Mitchell et al., 2018, p. 54), people who have cheated should feel especially ashamed if they identify more strongly with their organization because their behavior has not only failed to uphold a moral standard but may also have undermined the interests of others that they care about (i.e., those within the organization). Second, people who identify more strongly with a group are more likely to adopt the views and perspectives of the 
group (Turner, 1982). This suggests that individuals may judge their own cheating behavior more harshly when they identify more strongly with their organization. That is, strongly identifying with the organization may exacerbate the effects of cheating on shame. Finally, when people identify with a group, their identities are often dependent on their continued association with the group. Engaging in a behavior that violates a group's norms may be particularly likely to elicit shame among individuals who identify with the group because they may fear being rejected by or expulsed from the group, which would threaten their identity (Bedford \& Hwang, 2003). That is, shame may act as a social control mechanism. Taken together, we propose that the relationship between cheating and shame should be exacerbated when people identify more (versus less) strongly with their organization.

Hypothesis 5: Organizational identification moderates the relationship between cheating and shame, such that the relationship between cheating and shame is stronger when organizational identification is high (versus low).

To test our model, we begin by examining the relationship between cheating and overall justice values using a four-wave survey (Study 1). In Study 2, we examine the mediating role of shame in a controlled environment to rule out alternative explanations. In Study 3, a recall study, we replicate the mediating role of shame and contrast it with guilt and embarrassment. We also extend our findings by examining the moderating effect of organizational identification on the relationship between cheating and shame. In Studies 4 and 5, we replicate these findings in twopart surveys with full-time employees, which separate our predictor and criterion variables by one day and one week, respectively. In Study 6, we further test the generalizability of our findings in a field study within a single company. 


\section{STUDY 1}

In Study 1, we test the relationship between cheating and overall justice values (H1) using a four-wave survey with full-time employees. Using a measure of workplace cheating behavior that was validated for use in organizations (see Mitchell et al., 2018), we focus on cheating and overall justice values within ongoing workplace relationships and over time (i.e., by examining how changes in cheating are reflected in changes in overall justice values).

\section{Study 1 Method}

All studies reported in this article were approved by the Research Ethics Boards at Wilfrid Laurier University (protocol \# 4561; title: "Problem Solving”) and Ryerson University (protocol \# 2019-136; title: “Understanding Employees’ Perceptions at Work”).

\section{Participants and Procedure}

We recruited employees $(N=600)$ from the United States for a four-wave study. To enhance generalizability, we used Amazon's MTurk to recruit a heterogeneous sample (cf. Buhrmester, Kwang, \& Gosling, 2011). We followed best practices to ensure the quality of the online data, including screening for inattentiveness using five attention checks (e.g., "select agree to respond to this question"; Cheung, Burns, Sinclair, \& Sliter, 2017). Following recommendations from Marjanovic, Struthers, Cribbie, and Greenglass (2014), we set an a priori cut-off score of three correctly answered attention checks as an indication of attentiveness. None of our participants failed more than two attention checks and our results were substantively similar when participants who failed at least one attention check were excluded from the analyses. We followed the same approach in all subsequent studies and, in each case, excluding participants who failed at least one attention check resulted in substantively similar results. Thus, we did not exclude participants due to potential inattentiveness from any of the analyses. 
Participants completed four surveys. Given our theoretical arguments that cheating can influence overall justice values as people evaluate the implications of cheating for themselves and their social relationships - evaluations that can unfold quickly (Lazarus, 1991) - we selected time lags that temporally separated our variables while being short enough to be appropriate from a theoretical perspective (George \& Jones, 2000). The time 1 (T1) survey verified that participants met the inclusion criteria (i.e., being employed full-time and working in an environment with coworkers) and assessed cheating at baseline. The T2 survey was collected the day after T1 and assessed overall justice values at baseline. The T3 survey was collected a week later and assessed cheating using the same measure as T1. The T4 survey was collected the day after T3 and assessed overall justice values with the same measure as T2.

Participants were paid 1 USD per completed survey. Of the initial 600 respondents, 562 met the criteria for inclusion. We re-contacted participants who completed each round. The following numbers of respondents participated: 562 (T1), 432 (T2), 326 (T3), and 280 (T4). Participants who only completed Wave 1 reported higher levels of cheating behavior $(M=1.95$, $S D=1.00)$ than participants who completed all waves $(M=1.58, S D=.64, t(551)=-5.22, p<$ .001). We only included participants who completed all waves in our analyses, which provides a conservative test of our hypotheses. ${ }^{1}$ Given that our cheating measure required participants to report their cheating behavior over the past week, we removed 19 participants from the analyses who reported not having worked full-time during the week preceding the T1 or T3 surveys (e.g., due to illness or vacation days). The final sample $(N=261)$ was $51 \%$ female with an average age of 39.36 years $(S D=21.28)$, work experience of 17.66 years $(S D=10.68)$, and had worked in their current organization for an average of 7.06 years $(S D=6.44) ; 41 \%$ were managers.

\footnotetext{
${ }^{1}$ We followed the same approach for our other multi-wave studies (i.e., Studies 4 and 5).
} 


\section{Measures}

Workplace cheating behavior was assessed with Mitchell et al.'s (2018) scale (7 items; e.g., "Misrepresented work activity to make it look as though you have been productive"). We used the following instructions: "We are interested in better understanding workplace behavior. We are asking a large number of participants to indicate how often they have engaged in a wide range of behaviors that may occur in the workplace. You will be asked to rate several of those behaviors. Please indicate how often you engaged in each of the following workplace behaviors in the past week." The response scale ranged from never (1) to always (5). We assessed overall justice values using the protocol recommended by Holtz and Harold (2013). The question stem was: "Please imagine that your supervisor at work is about to make a decision that could impact you right now. How important is it to you that...". This stem was followed by the items from Ambrose and Schminke's (2009) overall justice scale (6 items; e.g., "You are treated fairly by your organization?"). The response scale ranged from not at all (1) to very much (5).

\section{Results and Discussion}

Table 1 presents the means, standard deviations, reliabilities, and correlations. We tested our hypotheses using structural equation modelling (SEM) in AMOS 25.0 (Arbuckle, 2017). Our structural regression model included cheating (measured at T1 and T3) and overall justice values (measured at T2 and T4) as latent variables with their corresponding items as indicators. The model was specified such that cheating (T3) predicted overall justice values (T4). To control for baseline levels, cheating (T3) was predicted by cheating (T1) and overall justice values (T4) was predicted by overall justice (T2). Cheating at baseline (T1) was also allowed to predict overall justice values (T2 and T4). We also specified an effect of overall justice values (T2) on cheating (T3) to explore this potential relationship. Thus, a fully recursive model was tested in which all 
earlier variables were allowed to predict all later variables.

Before testing our hypotheses, we conducted a confirmatory factor analysis (CFA) to confirm the factor structure of our measurement model, which included cheating (T1 and T3) and overall justice values (T2 and T4). Given that our model included repeated measures of cheating and overall justice values, we specified autocorrelations between the error terms of the repeated items (i.e., corresponding indicators) of these constructs (cf. Kline, 2011). ${ }^{2}$ The model had good fit: $\chi^{2}(280)=802.31 ;$ RMSEA $=.09 ; \mathrm{CFI}=.92$. Our 4-factor model also fit the data better than alternative models, including a 2-factor model in which all cheating items (T1 and T3) loaded on one factor and all overall justice values (T2 and T4) on a second factor $\left(\chi^{2}(285)=\right.$ 1798.15; RMSEA = .14; CFI = .76) and a 2-factor model in which all the items assessed at $\mathrm{T} 1$ and T2 loaded on one factor and those assessed at T3 and T4 on a second factor $\left(\chi^{2}(285)=\right.$ 1892.06; RMSEA = .15; CFI = .75).

While controlling for baseline levels of cheating and overall justice values, cheating (T3) was negatively associated with overall justice values (T4), $b=-.33, S E=.15, p=.02, R^{2}=.06$. H1 was supported. In an exploratory fashion, we also examined the relationship between overall justice values (T2) and cheating (T3) while controlling for baseline levels of cheating. The effect was non-significant, $b=.05, S E=.04, p=.19, R^{2}=.04$. Table 2 presents the results. Finally, we also examined several demographic variables - age, work experience, organizational tenure, and gender. None of these variables were significantly related to cheating or overall justice values and adding them to the models did not substantively affect our results. Given that including impotent control variables can bias the analyses and hinder interpretations (cf. Becker, 2005;

\footnotetext{
${ }^{2}$ We specified autocorrelations between the error terms of the repeated items in Study 1. We did not allow for correlations between error terms in the CFAs for Studies 2-6 since these did not include repeated measures.
} 
Carlson \& Wu, 2012), we did not include these variables in our final analyses.

Taken together, our results indicated that cheating is negatively associated with the extent to which individuals value receiving justice. This is consistent with our theoretical argument that cheating may motivate people to reduce the discrepancy between moral standards and their behavior (i.e., by aligning their preferences for justice with their behavior). Moreover, while cheating predicted overall justice values, the reverse did not hold. This provides confidence in our theorizing related to the temporal ordering of cheating and overall justice values.

\section{STUDY 2}

Study 1 provided evidence that cheating is negatively associated with overall justice values in a multi-wave study with full-time employees. In Study 2, we examine shame as the mechanism underlying this effect $(\mathrm{H} 2-\mathrm{H} 4)$. We also enhance methodological rigor by examining these relationships in a controlled environment to rule out alternative explanations as well as by assessing overall justice values as a latent construct to prevent mono-method bias and to ensure that our results replicate with this alternative conceptualization (see Colquitt \& Shaw, 2005).

\section{Study 2 Method}

\section{Participants and Procedure}

Participants $(N=183)$ were undergraduate students recruited from a North American university through a research participation system who received course credit for participating. This system involved the mass-testing of personality measures at the beginning of the semester. To assess cheating, we used an online version of a frequently used task from Wiltermuth (2011). Participants were shown a list of ten scrambled words and given two minutes to unscramble as many words as possible in the order in which the words were presented. They were told that better performance would increase their chances of winning $\$ 50$ in a raffle (in reality, all 
participants had an equal chance of winning). After two minutes, participants indicated how many words they had been able to unscramble consecutively. However, the third word on the list ("taguan") was extremely obscure and unlikely to be unscrambled. Thus, reported scores of three or more words were considered to be indicative of cheating (see Ruedy, Moore, Gino, \& Schweitzer, 2013; Wiltermuth, 2011). Next, participants completed our measures and were debriefed. Five participants were removed from the analyses for not following instructions. Given that the presence of outliers may bias the analyses by allowing a small number of atypical cases to unduly influence the results, we followed recommended practice and excluded 4 outliers that were more than 4 standard deviations from the mean on at least one measure (see Cohen, Cohen, West, \& Aiken, 2003). Five participants had less than 6 months of work experience. However, excluding these participants would have resulted in substantively similar results. Further, work experience did not significantly predict shame $\left(b=.03, S E=.03, p=.25, R^{2}=.01\right)$ or overall justice values $\left(b=.03, S E=.02, p=.17, R^{2}=.01\right)$ and including it as a covariate did not substantively affect the results. Thus, we did not remove these participants from the sample and did not control for work experience. The final sample $(N=174)$ was $58 \%$ female with an average age of 20.44 years $(S D=.92)$ and average work experience of 3.00 years $(S D=1.87)$.

\section{Measures}

Shame was assessed with a scale from Woodyatt and Wenzel (2014; 3 items; "I want to hide," "I feel small," "I can't face myself in the mirror"). The prompt was "Please select the responses that best describe how you feel right now". The response scale ranged from not at all (1) to very much (5). Overall justice values were assessed as a second-order latent variable with the justice dimensions as latent indicators. Using the same question stem as Study 1, we assessed distributive (4 items; e.g., "Your outcome reflects the effort you have put into your work?"), 
procedural (7 items; e.g., "The decision procedures are free of bias?"), and interpersonal justice (4 items; e.g., "Your supervisor treats you in a polite manner”) using Colquitt's (2001) scales.

We included measures of moral disengagement, generalized negative affect, and outcome favorability to rule out alternative theoretical explanations. Moral disengagement reflects the tendency to rationalize, justify, and/or distance oneself from unethical behaviors (Moore, Detert, Treviño, Baker, \& Mayer, 2012). Moral disengagement can occur after cheating and may diminish self-sanctions and promote motivated leniency (i.e., the downplaying of moral rules; e.g., Bandura, 1990; Shu et al., 2011). Thus, we examine state moral disengagement as an alternative explanation for the hypothesized effect of cheating on overall justice values. State moral disengagement was assessed with Shu et al.'s (2011) scale (6 items; e.g., "Sometimes getting ahead of the curve is more important than adhering to rules"). We also examine trait moral disengagement (measured as part of the mass-testing that was completed up to three months prior to the current study) because individual differences in the propensity to morally disengage can also predict unethical behavior (Moore et al., 2012) and may have implications for one's social relationships. Propensity to morally disengage was assessed with Moore et al.'s (2012) scale (8 items; e.g., "It is okay to spread rumors to defend those you care about"). Response scales for both measures ranged from strongly disagree (1) to strongly agree (5). Given our focus on shame as a mechanism, we wanted to ensure that any effects were due to the phenomenological experience of shame and its action tendencies (cf. Tangney, 1995) as opposed to generalized negative affect. Thus, we also examine generalized state negative affect as an alternative mediator. State negative affect was assessed with the negative affect subscale from Watson, Clark, and Tellegen (1988; 5-items; “afraid”; “upset”; "nervous"; "scared"; "distressed"). The response scale ranged from not at all (1) to very much (7). 
Finally, we wanted to rule out the alternative explanation that cheating influences overall justice values by impacting the extent to which people generally care about outcomes. Thus, we also explore the influence of cheating on the extent to which people value favorable outcomes (i.e., outcomes that are personally desirable or beneficial; Brockner, 2010). Outcome favorability values were assessed with Rodell and Colquitt's (2009) scale; this was modified to fit the current context and used the same question stem as overall justice values (4 items; "You benefit from the outcome of the decision process?"; "The outcome of the decision process is a good thing for you?"; "The outcome of the decision process is favorable to you"; "The outcome of the decision process is positive for you?"). Responses ranged from not at all (1) to very much (5).

\section{Results and Discussion}

Table 3 presents the means, standard deviations, reliabilities, and correlations. Consistent with past studies (e.g., Ruedy et al., 2013), approximately half (52\%) of our participants reported solving three or more words $(M=3.52, S D=2.09)$ and were thus considered "cheaters".

Cheating was dummy-coded (non-cheating $=0$; cheating $=1$ ). Before testing our hypotheses, we conducted a CFA to confirm the factor structure of our measurement model, which included cheating, shame, and overall justice values (modeled as a second-order reflective construct with three first-order latent indictors - interpersonal, procedural, and distributive justice values). Cheating was included as an observed (rather than latent) variable because it was dichotomous. Results indicated good fit, $\chi^{2}(147)=273.50 ;$ RMSEA $=.07 ; \mathrm{CFI}=.93$. Excluding the cheating variable from the CFA did not substantively affect model fit, $\chi^{2}(131)=242.49$; RMSEA $=.07$; $\mathrm{CFI}=.94$. Finally, our model fit the data better than alternative models, including a model in which the procedural and interpersonal justice values items loaded on a single factor $\left(\chi^{2}(148)=\right.$ 481.79; RMSEA = .11; CFI = .82), a model in which all justice values items loaded on one factor 
$\left(\chi^{2}(150)=623.95 ;\right.$ RMSEA $\left.=.14 ; \mathrm{CFI}=.75\right)$, and one in which all justice values and shame items loaded on one factor $\left(\chi^{2}(152)=784.39\right.$; RMSEA $=.16$; CFI $\left.=.66\right)$.

We tested our hypotheses using SEM in AMOS 25.0 (Arbuckle, 2017). Cheating was negatively associated with overall justice values, $b=-.17, S E=.07, p=.01, R^{2}=.05$. H1 was supported. Cheating was positively associated with shame, $b=.22, S E=.11, p=.04, R^{2}=.02$. $\mathrm{H} 2$ was supported. Shame was negatively associated with overall justice values, $b=-.10, S E=$ $.05, p=.03, R^{2}=.03 . \mathrm{H} 3$ was supported. Our complete mediation model was tested using bootstrapping (10,000 resamples) to calculate bias-corrected confidence intervals for the hypothesized indirect effect. The indirect effect of cheating on overall justice values via shame was non-significant at the conventional significance level but was in the predicted direction, indirect effect $=-.02,95 \%$ CI $[-.06, .00]$. H4 was not supported. ${ }^{3}$

We also examined the relationships between cheating and moral disengagement (state and trait), generalized state negative affect, and outcome favorability values to rule out these alternative explanations. Consistent with past research, cheating can enhance state moral disengagement $\left(b=.21, t(172)=2.11, p=.04, R^{2}=.03\right)$ and some people may be more likely to cheat than others due to differences in trait moral disengagement (logistic regression ; $b=.67, \chi^{2}$ $(1)=16.18, p<.001)$. However, cheating still positively predicts shame and influences the degree to which cheaters value justice beyond moral disengagement indicating that state and trait moral disengagement cannot account for our results.

Cheating did not significantly predict generalized negative affect $(b=-.14, S E=.18$,

\footnotetext{
${ }^{3}$ We also conducted analyses using transformations to enhance the normality (i.e., reduce the positive skew) of shame (Studies 2-6) and guilt (Studies 3-6) (see Cohen et al., 2003). The results of these analyses were substantively similar. Thus, we present our results without transformations to minimize problems (e.g., introducing complexities and creating interpretation issues) that can arise with transformation (Cohen et al., 2003; Draper \& Smith, 1998).
} 
$\left.t(171)=-.79, p=.43, R^{2}=.00\right) .{ }^{4}$ This provides support for the argument that it is the presence of shame (i.e., a moral emotion) that is driving the effects rather than increased negative affect.

Further, cheating did not significantly predict outcome favorability values $(b=-.07, S E=$ $\left..11, t(172)=-.66, p=.51, R^{2}=.00\right)$, ruling out the alternative explanation that cheating simply impacts the extent to which people generally value favorable outcomes. That is, cheaters (versus non-cheaters) value justice less rather than simply valuing outcomes of a decision process less.

Study 2 provides insight into why cheating may influence one's overall justice values cheating can elicit shame for failing to live up to a moral standard, which can detract from the value individuals place on receiving justice as a social reward. This study also provided further confidence in our findings by showing that moral disengagement (state/trait), negative affect, and outcome favorability values do not account for our results.

\section{STUDY 3}

In Study 3, we test our full moderated-mediation model using a study design in which participants are randomly assigned to conditions. We also examine the role of guilt - a moral emotion that tends to be experienced when people hold themselves responsible for a moral transgression (e.g., Baumeister, Stillwell, \& Heatherton, 1995; Tangney et al., 1996). Whereas guilt is focused on one's behavior and tends to motivate approach-oriented behaviors, shame is focused on evaluating how a behavior relates to one's core self and tends to motivate avoidance behaviors (i.e., shame can negatively impact one's self-views and compel people to hide or withdraw from others; Tangney et al., 1996, 2007). However, given that cheating may elicit guilt and/or shame, it is important to ensure that our effects are indeed being driven by shame.

\section{Study 3 Method}

\footnotetext{
${ }^{4}$ We used pairwise deletion for missing data in all studies, which is reflected in the reported degrees of freedom.
} 


\section{Participants and Procedure}

Full-time employees $(N=400)$ from the United States were recruited via Prolific (see Palan \& Schitter, 2018; Peer, Brandimarte, Samat, \& Acquisti, 2017) and paid 3.25 USD. The criterion for inclusion was full-time employment in an environment with coworkers; 377 respondents met these requirements but 13 were removed from the analyses for not following the instructions for the recall task. The final sample $(N=364)$ was $43.7 \%$ female with an average age of 33.80 years $(S D=9.42)$, work experience of 13.07 years $(S D=9.38)$, and tenure in their current organization of 5.31 years $(S D=5.57)$. Managers comprised $31.6 \%$ of the sample.

Participants were randomly assigned to one of two conditions in which they were asked to recall a recent workplace cheating behavior versus a neutral workplace behavior: "Please think about a time in the past month when you engaged in one of these behaviors. If you did not engage in any of these behaviors in the past month, please try to recall a time that you engaged in one of these behaviors that is as recent as possible. Please try to recall the event in as much detail as you can. Try to remember your thoughts and feelings at the time. Then, describe what happened in a few sentences." In the cheating condition, participants were presented with a list of seven common workplace cheating behaviors from Mitchell et al.'s (2018) cheating behavior scale (e.g., "Misrepresented work activity to make it look as though you have been productive," "Exaggerated work hours to look more productive"). By contrast, in the control condition, we modified the seven cheating items to reflect neutral (non-cheating) behavior (e.g., "Were productive," "Accurately reported the number of hours you had worked"). Following the recall task, participants completed our measures and manipulation check.

\section{Measures}

Shame was assessed using the same scale as Study 2. Guilt was assessed with a 3-item 
scale from Mosher and White (1981; "guilty," "remorseful," "sorry"). The response scale ranged from not at all (1) to very much (7). Overall justice values were assessed using the same scale as Study 1. Organizational identification was assessed with a scale from Smidts, Pruyn, and Van Riel (2001; 5-items, e.g., "I feel strong ties with my organization”). The response scale ranged from strongly disagree (1) to strongly agree (5).

Our manipulation check assessed perceived unethicality (5 items; "moral” reverse-coded, "ethical" reverse-coded, "against the rules," "against company policy," and "cheating”). The question stem was: "Please think about the workplace behavior that you were asked to recall and describe at the beginning of the survey. Then respond to the following statements: The behavior I was asked to describe was...". The response scale ranged from not at all (1) to very much (5).

\section{Results and Discussion}

Table 4 presents the means, standard deviations, reliabilities, and correlations. Our manipulation check indicated that participants in the cheating condition $(M=3.13, S D=.79)$ rated their own behavior as more unethical than those in the control condition $(M=1.52, S D=$ $.60), t(360)=21.79, p<.001$, Cohen's $d=2.29$. Thus, our manipulation was deemed effective.

Before testing our hypotheses, we conducted a CFA on our measures of shame, guilt, organizational identification, and overall justice values. The results indicated adequate fit, $\chi^{2}$ $(114)=277.87 ; \mathrm{RMSEA}=.06 ; \mathrm{CFI}=.97$. Our 4-factor measurement model fit the data better than alternative models, including a three-factor model in which the shame and guilt items loaded on a single factor, $\chi^{2}(116)=697.27 ; \mathrm{RMSEA}=.12 ; \mathrm{CFI}=.89$.

$\mathrm{H} 1$ and $\mathrm{H} 2$ were tested using independent samples t-tests. Participants in the cheating condition $(M=4.08, S D=.99)$ reported significantly lower overall justice values than those in the control condition $(M=4.27, S D=.80), t(362)=-.2 .04, p=.04$, Cohen's $d=.21$. H1 was 
supported. Participants in the cheating condition $(M=1.54, S D=.82)$ reported significantly more shame than those in the control condition $(M=1.37, S D=.70), t(362)=2.16, p=.03$, Cohen's $d=.23$. H2 was supported. H3 was tested using linear regression. Shame was negatively related to overall justice values, $b=-.14, S E=.06, t(362)=-2.18, p=.03, R^{2}=.01$. H3 was supported. To test $\mathrm{H} 4$, the experimental conditions were dummy-coded $($ control $=0$; cheating $=$ 1). Bootstrapping (10,000 resamples) was used to calculate bias-corrected confidence intervals (see Preacher \& Hayes, 2008; Shrout \& Bolger, 2002). The indirect effect of cheating on overall justice values via shame was significant, -.02, $S E=.02,95 \%$ CI [-.06, -.00]; the mediation model accounted for $2 \%$ of the variance in overall justice values. H4 was supported. To test H5, organizational identification was added to the mediation model as a first-stage moderator. The interaction between cheating and organizational identification significantly predicted shame, $b=$ $.19, S E=.08, t(360)=2.24, p=.03, \Delta R^{2}=.01$. Following Aiken and West (1991), we probed the interaction at low (one $S D$ below the mean) and high (one $S D$ above the mean) levels of organizational identification. The relationship between cheating and shame was stronger at high $(\hat{\mathrm{y}}=.32, S E=.11, p=.004)$ versus low levels of identification $(\hat{\mathrm{y}}=-.04, S E=.11, p=.73) . \mathrm{H} 5$ was supported.

We also conducted supplemental analyses in which guilt was examined as a parallel mediator to rule out the alternative explanation that the effect of cheating on overall justice values is driven by guilt instead of shame. Cheating (versus control) was positively associated with guilt $\left(b=1.26, S E=.16, t(362)=8.13, p<.001, R^{2}=.15\right)$. However, guilt did not significantly predict overall justice values $(b=-.01, S E=.03, t(360)=-.35, p=.73)$ and the indirect effect of cheating on overall justice values via guilt was non-significant, $-.01, S E=.05$, 
95\% CI [-.11, .09]. ${ }^{5}$ The negative relationship between shame and overall justice values remained in the predicted direction in the presence of guilt $(b=-.11, S E=.07, t(360)=-1.72, p=$ .09 ) as did the indirect effect of cheating on overall justice values via shame, $-.02, S E=.02,95 \%$ CI $[-.06, .00]$. However, the pairwise contrasts of the indirect effects indicated that the indirect effect via shame was not significantly larger than the indirect effect via guilt, .00, $S E=.06,95 \%$ CI $[-.10, .12]$. While these findings provide some confidence that shame and not guilt serves as an explanatory mechanism, we re-examine these relationships in Studies 4-6 to provide further insight into the effects of guilt and shame.

Using a different methodology, Study 3 provides further support for our argument that shame mediates the negative relationship between cheating and overall justice values. Further, although cheating predicted both shame and guilt, only shame predicted overall justice values and served as a significant mediator in this relationship. This finding is consistent with the theoretical distinctions between shame and guilt - whereas guilt is focused on one's behavior, shame is focused on how one's behavior relates to one's identity and self-views (Tangney et al., 2007). Further, organizational identification moderated the relationship between cheating and shame - this relationship was stronger when organizational identification was high (versus low). These findings reflect the close theoretical relationship between cheating, shame, and identity cheating can elicit shame because individuals have failed to uphold moral standards and this effect can be especially potent when it occurs within the context of a group that they strongly identify with since this behavior may also have negatively impacted those that they care about.

\footnotetext{
${ }^{5}$ Using a single-item measure ("embarrassed"), we also assessed embarrassment - a self-conscious emotion that is typically elicited by relatively trivial or humorous social transgressions (Tangey et al., 1996). Results indicated that cheating significantly predicted embarrassment, $b=.94, S E=.17, p<.001$. However, embarrassment did not significantly predict overall justice values, $b=.06, S E=.05, p=.20$. Moreover, the indirect effect of shame on overall justice via shame remained in the predicted direction when both guilt and embarrassment were included in the model as parallel mediators, $-.02, S E=.02,95 \%$ CI $[-.07, .00]$.
} 


\section{STUDY 4}

Study 3 provided a test of our full model using an experimental design with random assignment. Building on this, Study 4 re-tests the full model using a survey design that temporally separates our predictor and outcome variables as well as assesses cheating with a different measure to prevent mono-method bias.

\section{Study 4 Method}

\section{Participants and Procedure}

Full-time employees $(N=600)$ from the United States were recruited via MTurk to complete a two-part study. The T1 survey measured workplace cheating behavior, shame, guilt, and organizational identification. The T2 survey was collected the following day and assessed overall justice values. Participants were paid 1 USD per survey. The criteria for inclusion were full-time employment, working in an environment with coworkers, and not having participated in Study 1; 567 respondents met the criteria for inclusion and completed the T1 survey. They were re-contacted for the T2 survey, which was completed by 348 respondents. Given that the cheating measure required participants to report their workplace cheating behavior over the past week, we removed 18 participants from the analyses who reported not having worked full-time during the past week. The final sample $(N=330)$ was $45.2 \%$ female with an average age of 36.30 years $(S D=10.14)$, work experience of 16.21 years $(S D=11.58)$, and tenure in their current organization of 6.33 years $(S D=5.85)$. Managers comprised $38.7 \%$ of the sample.

\section{Measures}

Workplace cheating behavior was assessed using the same instructions as Study 1 but with four items from Bennett and Robinson's (2000) scale to prevent mono-method bias ("Falsified a receipt to get reimbursed for more money than you spent on business expenses," 
"Taken an additional or longer break than is acceptable at your workplace," "Came in late to work without permission," "Dragged out work in order to get overtime"). The response scale ranged from never (1) to always (5). Shame, guilt, organizational identification, and overall justice values were assessed using the same scales as Study 3.

\section{Results and Discussion}

Table 5 presents the means, standard deviations, reliabilities, and correlations. A CFA examining cheating, shame, guilt, overall justice values, and organizational identification had good fit, $\chi^{2}(179)=496.20 ;$ RMSEA $=.07 ; \mathrm{CFI}=.94$. Our 5-factor model fit the data better than alternative models, including a 4-factor model in which shame and guilt loaded on a single factor, $\chi^{2}(183)=901.81 ; \mathrm{RMSEA}=.11 ; \mathrm{CFI}=.87$. We tested our hypotheses using the same procedures as Study 3. Cheating was negatively associated with overall justice values, $b=-.23$, $S E=.05, t(327)=-4.73, p<.001, R^{2}=.06 . \mathrm{H} 1$ was supported. Cheating was positively related to shame, $b=.60, S E=.05, t(328)=12.23, p<.001, R^{2}=.31$. H2 was supported. Shame was negatively related to overall justice values, $b=-.26, S E=.05, t(327)=-5.89, p<.001, R^{2}=.10$. H3 was supported. Further, the indirect effect of cheating on overall justice values via shame was significant, $-.12, S E=.04,95 \%$ CI [-.20, -.05]; the mediation model accounted for $11 \%$ of the variance in overall justice values. H4 was supported. We added organizational identification to the mediation model as a first-stage moderator to test H5. The interaction between cheating and organizational identification significantly predicted shame, $b=.13, S E=.06, t(324)=2.08, p=$ $.04, \Delta R^{2}=.01$. Following Aiken and West (1991), we probed the interaction at low (one $S D$ below the mean) and high (one $S D$ above the mean) levels of organizational identification. The relationship between cheating and shame was stronger at high $(\hat{\mathrm{y}}=.71, S E=.07, p<.001)$ versus low levels of identification $(\hat{\mathrm{y}}=.47, S E=.08, p<.001)$. H5 was supported. 
As in Study 3, we also conducted supplemental analyses with guilt as a parallel mediator to rule out the alternative explanation that the effect of cheating on overall justice values is driven by guilt instead of shame. Cheating was positively related to guilt, $b=.94, S E=.08$, $t(327)=11.03, p<.001, R^{2}=.27$. However, guilt did not predict overall justice values $(b=.02$, $S E=.03, t(325)=.72, p=.47)$ and the indirect effect via guilt was non-significant, $.02, S E=$ $.03,95 \%$ CI $[-.04, .09]$. Pairwise contrasts indicated that the indirect effect via shame was significantly larger than the indirect effect via guilt, -.16, SE $=.07,95 \%$ CI [-.30, -.03]. Importantly, the relationship between shame and overall justice values $(b=-.23, S E=.06, t(325)$ $=-3.81, p<.001)$ and the indirect effect of cheating on overall justice values via shame $(-.13, S E$ $=.04,95 \% \mathrm{CI}[-.23,-.05])$ remained significant in the presence of guilt.

Using a survey design (with the predictor and outcome variables temporally separated), Study 4 replicates the findings from Study 3 thereby providing further evidence that shame (but not guilt) mediates the relationship between cheating and overall justice values and that the effect of cheating on shame is stronger for those who more strongly identify with their organization.

\section{STUDY 5}

We re-test our complete theoretical model in Study 5 using a survey design with a different measure of cheating (to prevent mono-method bias) and a longer temporal separation between our predictor and outcome variables (one week versus one day in Study 4).

\section{Study 5 Method}

\section{Participants and Procedure}

Full-time employees $(N=600)$ from the United States were recruited via Prolific to complete a two-part survey. We followed the same inclusion criteria and protocols as Study 4 but increased the time separation between our measures of cheating (T1) and overall justice (T2) 
from one day to one week. Participants were paid 2.20 USD for completing the T1 survey $(N=$ $599)$ and 4.40 USD for the T2 survey $(N=390)$. Given that the cheating measure required participants to report their workplace cheating behavior over the past week, we removed 21 participants who reported not having worked full-time during the past week. We also removed 4 outliers that were more than 4 standard deviations from the mean (on overall justice values; see Cohen et al., 2003). The final sample $(N=365)$ was $44.7 \%$ female with an average age of 34.09 years $(S D=8.76)$, work experience of 13.73 years $(S D=8.84)$, and tenure in their current organization of 5.35 years $(S D=4.85)$. Managers comprised $33.2 \%$ of the sample.

\section{Measures}

Workplace cheating behavior was assessed with the same measure as Study 1; shame, guilt, overall justice values, and organizational identification were assessed with the same measures as Study 3.

\section{Results and Discussion}

Table 6 presents the means, standard deviations, reliabilities, and correlations. A CFA with cheating, shame, guilt, overall justice values, and organizational identification indicated good fit, $\chi^{2}(242)=487.53 ;$ RMSEA $=.05 ; \mathrm{CFI}=.96$. Our 5-factor model fit the data better than alternative models, including a 4-factor model in which shame and guilt loaded on a single factor, $\chi^{2}(246)=810.26 ;$ RMSEA $=.08 ; \mathrm{CFI}=.91$.

Our hypotheses were tested with the same procedures as Studies 3 and 4. Cheating was negatively related to overall justice values, $b=-.19, S E=.05, t(363)=-3.76 p<.001, R^{2}=.04$. $\mathrm{H} 1$ was supported. Cheating was positively related to shame, $b=.42, S E=.06, t(363)=7.32, p$ $<.001, R^{2}=.13$. H2 was supported. Shame was negatively related to overall justice values, $b=$ $-.13, S E=.04, t(363)=-.13, p=.004, R^{2}=.02 . \mathrm{H} 3$ was supported. The indirect effect of cheating 
on overall justice values via shame was not significant but was in the predicted direction, -.03, $S E=.03,95 \%$ CI $[-.09, .01]$; the mediation model accounted for $5 \%$ of the variance in overall justice values. H4 was not supported. ${ }^{6}$ The interaction between cheating and organizational identification had a significant effect on shame, $b=.12, S E=.06, t(361)=2.13, p=.03, \Delta R^{2}=$ .01. Consistent with Study 4, cheating had a stronger effect on shame at high $(\hat{\mathrm{y}}=.54, S E=.08, p$ $<.001)$ than at low levels of identification $(\hat{\mathrm{y}}=.30, S E=.08, p<.001)$. H5 was supported.

We conducted supplemental analyses with guilt as a parallel mediator. Cheating was positively related to guilt, $b=.85, S E=.11, t(363)=7.81, p<.001, R^{2}=.14$. However, guilt did not significantly predict overall justice values $(b=.02, S E=.03, t(361)=.78, p=.44)$ and the indirect effect via guilt was non-significant, .02, SE $=.02,95 \%$ CI [-.03, .07]. Pairwise contrasts indicated that the indirect effect via shame was not significantly larger than the indirect effect via guilt, -.06, $S E=.05,95 \%$ CI [-.15 .03]. Importantly, the inclusion of guilt did not alter the results for shame; the relationship between shame and overall justice values $(b=-.10, S E=.06, p=.06)$ and the indirect effect of cheating on overall justice values via shame, 95\% CI [-.10, .01], remained substantively unchanged in the presence of guilt.

Study 5 replicated our full model using a different cheating measure and with increased temporal separation between our predictor and outcome variables (one week versus one day). Consistent with Studies 3 and 4, cheating can elicit shame and this effect is exacerbated for

\footnotetext{
${ }^{6} \mathrm{We}$ also examined trait justice sensitivity (measured at T2), which captures the extent to which people identify justice as an important moral principle (Schmitt, Gollwitzer, Maes, \& Arbach, 2005; 10 items, $\alpha=.86$, e.g., "It bothers me when someone gets something they don't deserve"). Justice sensitivity was positively associated with overall justice values $\left(b=.20, S E=.06, t(363)=3.13, p=.001, R^{2}=.03\right)$ and the results were substantively similar when this variable was included as a covariate; the effect of shame on overall justice values remained significant, $b$ $=-.11, S E=.05, t(361)=-2.39, p=.02$. Further, the indirect effect of cheating on overall justice values via shame remained non-significant but in the predicted direction, $-.05, S E=.03,95 \% \mathrm{CI}[-.11, .00]$, as did the interaction between cheating and organizational identification, $b=.11, S E=.06, t(360)=1.89, p=.06$. This rules out the alternative explanation that the relationship between cheating and justice values may be driven by people who do not identify justice as an important principle (who may cheat more and care less about receiving fair treatment).
} 
employees who are highly identified with their organization. In turn, shame can negatively impact social dynamics within the organization by undermining the value that people place on justice. This replication provides further confidence in the generalizability of our findings.

\section{STUDY 6}

Study 6 re-tests our full moderated-mediation model using a sample of full-time employees from a single organization in North America.

\section{Participants and Procedure}

The data presented in this article were part of a broader data collection effort. Employees $(N=1035)$ from a North American company in the insurance industry were invited to participate by email. A total of 239 employees responded to the online survey. Given that participants had to report their workplace cheating behavior over the past week for our measure, only respondents who reported that they worked full-time during the past week were included in the analyses. The final sample $(N=187)$ was $66.8 \%$ female with an average age of 43.69 years $(S D=12.44)$ and tenure in the organization of 9.36 years $(S D=8.95)$. Managers comprised $23.5 \%$ of the sample. Respondents were informed that their participation was voluntary and anonymous. Further, the company would not have access to any individual data, but an aggregated report would be provided to the company. Participants were allowed to complete the survey on company time and were redirected to a second survey (to preserve anonymity) in which they could enter their email address to be entered into a raffle to win $\$ 50$ (one prize per 50 respondents).

\section{Measures}

At the request of the company, we abbreviated some measures. Workplace cheating behavior was assessed with three items from the Study 1 scale ("Misrepresented work activity to make it look as though you have been productive," "Made it look like you were working when 
you were not," "Made up work activity to look better"). Shame and guilt were assessed with the scales from Study 3. Overall justice values were assessed with two items from the Study 1 scale ("You are treated fairly by your organization," "Your organization treats its employees fairly"). Organizational identification was assessed with two items from the scale used in Study 3 ("I feel strong ties with [name of company]," "I experience a strong sense of belonging to [name of company]"). Question stems and response scales were the same as previous studies.

\section{Results and Discussion}

Table 7 presents the means, standard deviations, reliabilities, and correlations. A CFA with cheating, shame, guilt, overall justice values, and organizational identification indicated good fit, $\chi^{2}(55)=94.77 ;$ RMSEA $=.06 ; \mathrm{CFI}=.97$. Our 5-factor model fit the data better than alternative models, including a 4-factor model in which shame and guilt loaded on a single factor, $\chi^{2}(59)=266.88 ;$ RMSEA $=.14 ; \mathrm{CFI}=.86$.

We used the same procedures as Studies 3-5 to test our hypotheses. Cheating was negatively associated with overall justice values, $b=-.40, S E=.14, t(185)=-2.95 p=.004, R^{2}=$ $.05 . \mathrm{H} 1$ was supported. Cheating was positively associated with shame, $b=.34, S E=.10, t(185)$ $=3.50, p=.001, R^{2}=.06 \mathrm{H} 2$ was supported. Shame was negatively related to overall justice values, $b=-.32, S E=.10, t(185)=-3.22, p=.002, R^{2}=.05 . \mathrm{H} 3$ was supported. The indirect effect of cheating on overall justice values via shame was significant, -..09, $S E=.07,95 \% \mathrm{CI}$ $[-.29,-.00]$; the mediation model accounted for $8 \%$ of the variance in overall justice values. H4 was supported. However, the interaction between cheating and organizational identification did not significantly predict shame, $b=-.03, S E=.08, t(180)=-.32, p=.75, \Delta R^{2}=.00$. H5 was not supported. This may be due to the moderately strong negative relationship between cheating and organizational identification in this study (see Table 7). We further discuss this finding below. 
We conducted supplemental analyses with guilt as a parallel mediator. Cheating was positively related to guilt, $b=.70, S E=.26, t(180)=2.68, p=.001, R^{2}=.04$. However, guilt did not significantly predict overall justice values $\left(b=.00, S E=.04, t(180)=.04, p=.97, R^{2}=.00\right)$ and the indirect effect via guilt was non-significant, .02, SE $=.02,95 \%$ CI $[-.03, .07]$. Pairwise contrasts indicated that the indirect effect via shame was significantly larger than the indirect effect via guilt, $-.14, S E=.08,95 \%$ CI $[-.34,-.02]$. The results for shame remained substantively similar in the presence of guilt; shame remained negatively and significantly related to overall justice values $(b=-.31, S E=.11, p=.005)$ and the indirect effect of cheating on overall justice values via shame remained significant, $-.10, S E=.07,95 \%$ CI [-.28, -.00].

\section{GENERAL DISCUSSION}

Given the pervasive and detrimental impact of cheating for organizations, it is critical to not only understand when and why people cheat, but also how cheating impacts individuals and the social dynamics around them. Although previous research has shown that cheating can have damaging consequences for organizations (e.g., Dickson, Smith, Grojean, \& Ehrhart, 2001), our studies indicated that these behaviors can also have aversive intrapersonal and interpersonal outcomes. More precisely, cheating can elicit shame - a moral emotion associated with feeling diminished and inferior to others - which can reduce the value that people place on others upholding justice for them. We discuss the theoretical implications of our findings below.

\section{The Consequences of Cheating Within Organizations}

Our studies show that cheating can have damaging effects by undermining justice - an important social facilitator that allows people to effectively work together by serving as the "glue" in social relationships (Cropanzano et al., 2007). Justice is associated with a broad range of positive outcomes for employees and organizations (e.g., Colquitt et al., 2013) and serves 
critical functions in organizations (e.g., acting as a social control on leaders' behaviors; Oç et al., 2015). However, our findings indicate that people may not value justice to the same extent after cheating. When individuals place less value on justice, organizations may not reap the benefits associated with providing justice to their employees (e.g., enhanced performance, citizenship behaviors; Colquitt et al., 2001, 2013). Thus, by undermining this critical social facilitator, cheating may not only impact individuals and organizations in the short term but may also have further negative downstream implications for employees and organizations.

Building on the above, our findings highlight the importance of further examining the downstream consequences of cheating for the individual and with outcomes that are especially relevant within organizational settings. For example, although individuals may cheat to enhance their performance in the short term (Mitchell et al., 2018), these effects are likely to be relatively short-lived. Given that cheating is associated with individuals placing less value on justice, people who cheat can undermine their social relationships, which may detract from their own performance as well as the performance of others within their group. That is, any short-term benefits in performance that arise from cheating may be offset by long-term detriments to performance by detracting from the effectiveness of social facilitators (i.e., justice). Thus, our findings demonstrate that cheating behaviors not only have important and detrimental implications for organizations but can also have aversive consequences for individuals who engage in cheating behavior as well as for the social dynamics within organizations.

\section{The Importance of Shame as a Mediating Mechanism}

Our research highlights the fundamental role of shame within the context of cheating shame served as a critical mechanism linking cheating with overall justice values. This finding is theoretically significant for several reasons. First, the behavioral ethics literature has focused on 
cognitive and behavioral strategies (e.g., justifying, rationalizing, and distancing) that can emerge following cheating (e.g., Shu et al., 2011). However, we argued that the intentional, volitional, and self-interested nature of cheating may be especially likely to elicit shame. That is, since people may be less able to justify cheating as being warranted (e.g., to help the greater good), they may view these behaviors as being closer to their own identity and therefore be likely to experience shame. Our studies highlight the influential role of shame as an emotional outcome of cheating and as a mechanism underlying the relationship between cheating and overall justice values. Importantly, the effects of shame were influential beyond moral disengagement (i.e., attempts to rationalize or justify), suggesting that it is critical to consider the role of emotions within the context of cheating. Moreover, these findings suggest that future research should further explore the relationship between different forms of unethical behaviors and discrete emotions. For example, people may experience pride if they believe their unethical actions were needed to help the organization or schadenfreude (i.e., pleasure at the suffering of others) if they believe that their unethical actions harmed someone who deserved it. Thus, we encourage behavioral ethics researchers to further explore how theoretical distinctions between various unethical behaviors may provide insight into the discrete emotions that can be elicited.

Second, there have been numerous calls in the literature to further explore the effects of discrete emotions (e.g., Barclay \& Kiefer, 2019). Given that discrete emotions are associated with specific characteristics and action tendencies (Lazarus, 1991), this approach can enhance our understanding of people's experiences and more precisely predict their reactions. Our studies highlight the importance of examining shame, which has traditionally been underemphasized in the literature (Cropanzano, Anthony, Daniels, \& Hall, 2017). By focusing on shame, we provide insights into how individuals emotionally respond to cheating and how shame can impact social 
dynamics by diminishing the value that individuals place on justice. Moreover, our findings provide further evidence for the distinctions between shame and other discrete emotions, such as guilt and embarrassment. Although cheating can predict each of these emotions, only shame was related to overall justice values. This not only underscores the importance of shame but also understanding the differential effects of various discrete emotions. It may be fruitful for future research to further explore the unique downstream implications of guilt and embarrassment.

Third, whereas previous research examining shame in the context of cheating has focused on its positive effects (e.g., eliciting exemplification behaviors; Bonner et al., 2017), our findings highlight both the functional and dysfunctional consequences of shame within organizational contexts. Shame is functional because it provides immediate (and aversive) feedback to the individual that can curtail future unethical behavior (Tracy \& Robins, 2007). However, shame can also be dysfunctional by undermining the interpersonal processes that govern effective social dynamics in the workplace (e.g., by detracting from the value individuals place on justice, which is an important social facilitator reflecting one's social standing and worth). This suggests that it is critical for scholars to take a more nuanced approach to emotions in the workplace that recognizes the importance of emotions while also accounting for their complexity.

\section{Understanding the Importance of Identity in the Context of Cheating}

Our research also highlights the importance of identity within the context of cheating. More specifically, cheating can reflect one's identity concerns via the elicitation of shame - an emotion that arises when one's ego-identity is threatened (e.g., when one's behaviors fail to uphold moral standards; Lazarus, 1991). Further, the relationship between workplace cheating behaviors and shame can be exacerbated for people who are more (versus less) strongly identified with their organization. That is, when one's identity is aligned with one's organization, 
cheating can be particularly aversive for the individual by further enhancing shame. On the one hand, this suggests that identity may serve as a potent social control mechanism by generating an aversive state (i.e., shame) that is likely to discourage future cheating behavior. On the other hand, the identity concerns that can arise after engaging in cheating may also prompt the individual to place less value on justice, an important social facilitator. When individuals place less value on justice, this may create other downstream aversive states by reducing one's sense of self-worth and standing and/or by prompting further withdrawal behaviors. Future research should further examine the long-term effects of shame within organizations and develop interventions that can maintain the functional aspects of shame (i.e., curtailing unethical behaviors) while mitigating the potential detrimental long-term effects on one's relationships.

While the interaction between cheating and organizational identification in predicting shame replicated in Studies 3-5, the interaction was not significant in Study 6. There are several potential explanations for these differences. For example, Studies 3-5 used larger heterogeneous samples whereas Study 6 used a smaller sample of employees from a single organization. Moreover, there was a moderately strong negative relationship observed for cheating and organizational identification in Study $6(r=-.29)$ versus the weaker correlations in the other studies ( $r$ range -.13 to -.11), which may have been due to the use of a shortened measure in Study 6. Given that the interaction did not replicate in Study 6, we suggest that readers interpret this effect with caution and that future studies further examine this relationship.

\section{Facilitating Integration between Behavioral Ethics and Organizational Justice}

Although scholars have called for a closer integration of the behavioral ethics and justice literatures (e.g., Cropanzano \& Stein, 2009; Schminke et al., 1997), empirical research doing so has been slow to emerge. By examining the relationship between cheating and justice, our 
studies make important contributions to the behavioral ethics and justice literatures as well as highlight opportunities for further integration. For example, whereas the justice literature has typically considered unethical behavior as an outcome of perceived injustice (e.g., Colquitt et al., 2001), our results indicate that unethical behavior can also serve as an antecedent to justice. By contrast, the behavioral ethics literature has focused on identifying antecedents of unethical behavior (Gino, 2015). However, our research shows that unethical behavior can have important outcomes within the context of justice. Thus, our research provides insights into the nomological network of these constructs and highlights the different roles that these constructs can play (e.g., antecedents and outcomes). Further, this suggests that it may be important for future research to further explore the reciprocal effects between ethics and justice.

Our findings also suggest that viewing justice as a motivated phenomenon can provide another point of integration. Within the justice literature, scholars have called for an enhanced understanding of how people's needs and motivations can influence their justice perceptions (e.g., Barclay et al., 2017). Our finding that cheating can influence the value that individuals place on justice supports the notion that people's needs/preferences for justice can fluctuate and that cheating and moral emotions can be important antecedents of these effects. Thus, these findings contribute to our theoretical understanding of how employees' motivations for pursuing justice can be influenced by their own behaviors and emotions.

These findings also indicate that a closer integration of the behavioral ethics and justice literatures may be achieved through moral emotions. More specifically, moral emotions are foundational in both literatures; examining commonalities in their treatment across the literatures may aid scholars in identifying points of integration whereas exploring distinctions may provide a more nuanced understanding of moral emotions and how they operate in different contexts. 
Taken together, we encourage behavioral ethics and justice scholars to continue exploring ways in which these literatures can inform each other since this will undoubtedly enhance our understanding and ability to effectively manage complex issues within the workplace.

\section{STRENGTHS, LIMITATIONS, AND OPPORTUNITIES FOR FUTURE RESEARCH}

We triangulated our results across six studies using samples recruited from disparate sources (e.g., an organization, online samples, and a research pool) as well as laboratory and field methodologies (i.e., a four-wave survey, a task using a behavioral measure of cheating behavior, a recall task, two-part surveys, and a cross-sectional field study with employees from a single organization). We also used different methods and measures for capturing cheating and overall justice values to prevent mono-method bias. We ensured that our laboratory study had psychological realism by including actual behaviors, a task that was relevant to the participants, and real financial outcomes (see Carlsmith, Ellsworth, \& Aronson, 1976). In five of our studies, we examined cheating behaviors in workplace contexts with samples of full-time working employees. While online paid samples (e.g., MTurk and Prolific) have been criticized for having "low stakes" that may increase non-conscientious responding, we employed best practices to assess inattentive responding and also to minimize potential method bias (e.g., by ensuring confidentiality, randomizing items within question blocks, using measures with disparate scale properties, and including studies in which our predictor and criterion variables were temporally separated; cf. Podsakoff, MacKenzie, \& Podsakoff, 2012). Nonetheless, future research should further examine these relationships with other samples and methodologies.

Our research question focused on workplace cheating behavior - a type of unethical behavior that focuses on gaining advantages for oneself (Mitchell et al., 2018; Shu et al., 2011). However, people may also engage in other types of misconduct, including unethical behavior 
that is intended to help others in the organization (Umphress \& Bingham, 2011) or unethical behavior that is intended to harm others in the absence of apparent self-gain (Mitchell et al., 2018). Given that these behaviors are likely to be associated with disparate motivations, future research may benefit from examining differential outcomes for these constructs.

Given the distinct effects of shame (versus guilt and embarrassment), it may also be insightful to further explore the differential effects of these discrete emotions within the context of cheating and with other unethical behaviors. For example, shame likely emerged in our studies because cheating was a volitional behavior. However, people may experience disgust if they believe that they "had to" engage in unethical behavior (e.g., if powerful others pressured them to engage in the behavior) or pride if they believe that the unethical behavior was needed to overcome an unfair system. These different discrete emotions may have disparate downstream implications (Lazarus, 1991). Future research should examine other discrete emotions that may arise in the context of cheating and other unethical behaviors since this can deepen our understanding of the interplay between unethical behaviors and emotions, which may also expand the scope of dependent variables that should be examined in this context.

Finally, given our emphasis on understanding identity within the context of cheating, we examined the moderating role of organizational identification - a form of social identity. However, personal identity (e.g., moral identity) and other contextual factors may also serve as potential boundary conditions. For instance, the relationship between cheating and shame may be enhanced for people who care deeply about being a moral person (i.e., high moral identity). Alternatively, group norms and contextual factors may influence how individuals view the ethicality of cheating behavior, which may influence their emotions and subsequent reactions. 
Although employees may cheat to accrue benefits (e.g., to appear more productive and valuable to others in the organization; Mitchell et al., 2018), the irony is that these behaviors can be aversive to individuals (e.g., by diminishing feelings of self-worth and standing), undermine their social relationships (e.g., by detracting from the value of justice), and set the stage for longterm detrimental outcomes. Thus, cheating can have negative outcomes for the individual that also detract from functional social dynamics in the workplace. Moreover, these effects can be especially impactful for employees who are highly identified with the organization. Although organizational identification is often associated with beneficial outcomes (e.g., enhanced in-role and extra-role behaviors, reduced turnover, increased satisfaction and attachment; see Riketta, 2005, for a meta-analytic review), our findings suggest that being highly identified may be a detriment in the context of cheating by exacerbating effects on shame and, by extension, the value that people place on justice after cheating. Thus, managers should recognize that highly identified employees may be the most profoundly impacted by these behaviors.

From an organizational perspective, our finding that cheating is negatively associated with valuing justice is concerning because this may have downstream implications that can also impact the organization and its leaders. For example, studies have shown that supervisors who do not receive candid feedback (complaints) about their unfair behaviors can become increasingly unfair over time (Oç et al., 2015). By extension, when employees cheat, they may be less likely to respond to leaders' justice violations, thereby creating a "slippery slope" that allows for further violations. In other words, cheating behaviors may "trickle up" by eroding social controls on leaders' behaviors as well as by weakening the justice norms and climate in the organization. This possibility underscores the importance of preventing and effectively managing cheating because these behaviors may have pervasive effects within organizations. 
Our findings also suggest the importance of taking a multi-pronged approach to preventing and managing unethical behavior in the workplace. For example, organizations can employ interventions that prevent behaviors from happening (i.e., primary), minimize the negative effects of the behavior (i.e., secondary), or ameliorate the aftermath of the situation (i.e., tertiary interventions) (Quick, Murphy, Hurrell, \& Orman, 1992). Although prevention is often emphasized, our findings indicate that it is also important to mitigate the damage of unethical behavior as well as ameliorate the situation after unethical behavior has occurred, especially in light of the damaging consequences of these behaviors. Moreover, when engaging in secondary interventions, organizations should carefully consider where to intervene. For example, while it is functional for individuals to experience shame because this can curtail future cheating, it can be dysfunctional for shame to undermine the social dynamics that are critical for effective organizational functioning. Thus, managers may find it more useful to focus on managing the implications of shame than minimizing the emergence of shame in the wake of cheating. Further, organizations may find it helpful to reestablish the social and moral norms that have been broken by the cheating behavior to prevent the escalation of unethical behaviors in the workplace. Restorative justice strategies, which reestablish norms in the wake of transgressions, may be particularly helpful towards this end (e.g., Wenzel, Okimoto, Feather, \& Platow, 2008).

\section{CONCLUSION}

Cheating not only has extremely damaging effects for the organization (e.g., reduced financial performance, damaged reputations), but can also have significant implications for employees and the social dynamics within organizations. Our research highlights that cheating can reduce the value that people place on receiving justice - a critical social facilitator that can be rewarding for individuals by enhancing their standing and self-worth. Moreover, our findings 
highlight the importance of shame in this context - while shame can help people recognize that their behavior may not be appropriate, it can also undermine the social dynamics of relationships in the aftermath of cheating. Practically, this suggests that organizations need to recognize and effectively manage the consequences of cheating and shame for individuals within organizations. 


\section{REFERENCES}

Aiken, L. S., \& West, S. G. (1991). Multiple regression: Testing and interpreting interactions. Newbury Park, CA: Sage.

Ambrose, M. L., \& Schminke, M. (2009). The role of overall justice judgments in organizational justice research: A test of mediation. Journal of Applied Psychology, 94, 491-500. doi: $10.1037 / \mathrm{a} 0013203$

Arbuckle, J. L. (2017). Amos (Version 25.0) [Computer Program]. Chicago: IBM SPSS.

Aquino, K., \& Reed II, A. (2002). The self-importance of moral identity. Journal of Personality and Social Psychology, 83, 1423-1440. doi: 10.1037/0022-3514.83.6.1423

Ariely, D. (2012, May 26). Why we lie. The Wall Street Journal, p. C1.

Ashforth, B. E., \& Mael, F. (1989). Social identity theory and the organization. Academy of Management Review, 14, 20-39. doi: 10.5465/amr.1989.4278999

Bandura, A. (1990). Selective activation and disengagement of moral control. Journal of Social Issues, 46, 27-46. doi: 10.1111/j.1540-4560.1990.tb00270.x

Barclay, L. J., Bashshur, M. R., \& Fortin, M. (2017). Motivated cognition and fairness: Insights, integration, and creating a path forward. Journal of Applied Psychology, 102, 867-889. doi: 10.1037/apl0000204

Barclay, L. J., \& Kiefer, T. (2019). In the aftermath of unfair events: Understanding the differential effects of anxiety and anger. Journal of Management, 45, 1802-1829. doi: $10.1177 / 0149206317739107$

Baumeister, R. F., Stillwell, A. M., \& Heatherton, T. F. (1995). Personal narratives about guilt: Role in action control and interpersonal relationships. Basic and Applied Social Psychology, 17, 173-198. doi: 10.1080/01973533.1995.9646138 
Becker, T. (2005). Potential problems in the statistical control of variables in organizational research. Organizational Research Methods, 8, 274-289. doi: 10.1177/1094428105278021

Bedford, O., \& Hwang, K. K. (2003). Guilt and shame in Chinese culture: A cross-cultural framework from the perspective of morality and identity. Journal for the Theory of Social Behaviour, 33, 127-144. doi: 10.1111/1468-5914.00210

Bennett, R. J., \& Robinson, S. L. (2000). Development of a measure of workplace deviance. Journal of Applied Psychology, 85, 349-360. doi: 10.1037/0021-9010.85.3.349

Bonner, J. M., Greenbaum, R. L., \& Quade, M. J. (2017). Employee unethical behavior to shame as an indicator of self-image threat and exemplification as a form of self-image protection: The exacerbating role of supervisor bottom-line mentality. Journal of Applied Psychology, 102, 1203-1221. doi: 10.1037/ap10000222

Brockner, J. (2010). A contemporary look at organizational justice: Multiplying insult times injury. New York: Routledge.

Buhrmester, M., Kwang, T., \& Gosling, S. D. (2011). Amazon's Mechanical Turk: A new source of inexpensive, yet high-quality, data? Perspectives on Psychological Science, 6, 3-5. doi: $10.1177 / 1745691610393980$

Carlsmith, J. M., Ellsworth, P., \& Aronson, E. (1976). Methods of research in social psychology. Reading, MA: Addison Wesley.

Carlson, K. D., \& Wu, J. (2012). The illusion of statistical control: Control variable practice in management research. Organizational Research Methods, 15, 413-435. doi: $10.1177 / 1094428111428817$

Cheung, J. H., Burns, D. K., Sinclair, R. R., \& Sliter, M. (2017). Amazon Mechanical Turk in organizational psychology: An evaluation and practical recommendations. Journal of 
Business and Psychology, 32, 347-361. doi: 10.1007/s10869-016-9458-5

Cohen, J., Cohen, P., West, S. G., \& Aiken, L. S. (2003). Applied multiple regression/correlation analysis for the behavioral sciences (3rd ed.). Mahwah, NJ: Erlbaum.

Colquitt, J. A. (2001). On the dimensionality of organizational justice: A construct validation of a measure. Journal of Applied Psychology, 86, 386-400. doi: 10.1037/00219010.86 .3 .386

Colquitt, J. A., Conlon, D. E., Wesson, M. J., Porter, C. O., \& Ng, K. Y. (2001). Justice at the millennium: A meta-analytic review of 25 years of organizational justice research. Journal of Applied Psychology, 86, 425-445. doi: 10.1037/0021-9010.86.3.425

Colquitt, J. A., Scott, B. A., Rodell, J. B., Long, D. M., Zapata, C. P., Conlon, D. E., \& Wesson, M. J. (2013). Justice at the millennium, a decade later: A meta-analytic test of social exchange and affect-based perspectives. Journal of Applied Psychology, 98, 199-236. doi: $10.1037 / \mathrm{a} 0031757$

Colquitt, J. A., \& Shaw, J. C. (2005). How should organizational justice be measured? In J. Greenberg \& J. A. Colquitt (Eds.), Handbook of organizational justice (pp. 113-152). Mahwah, NJ: Lawrence Erlbaum.

Cropanzano, R., Anthony, E., Daniels, S., \& Hall, A. (2017). Social exchange theory: A critical review with theoretical remedies. Academy of Management Annals, 11, 1-38. doi: 10.5465/annals.2015.0099

Cropanzano, R., Bowen, D. E., \& Gilliland, S. W. (2007). The management of organizational justice. Academy of Management Perspectives, 21, 34-48. doi: 10.5465/AMP.2007.27895338

Cropanzano, R., \& Stein, J. H. (2009). Organizational justice and behavioral ethics: Promises 
and prospects. Business Ethics Quarterly, 19, 193-233. doi: 10.5840/beq200919211

de Waal, F. (2006). Primates and philosophers: How morality evolved. Princeton, NJ: Princeton University Press.

Draper, N. R., \& Smith, H. (1998). Applied regression analysis (3rd ed.). New York: Wiley.

Dickson, M. W., Smith, D. B., Grojean, M. W., \& Ehrhart, M. (2001). An organizational climate regarding ethics: The outcome of leader values and the practices that reflect them. Leadership Quarterly, 12, 197-217. doi: 10.1016/S1048-9843(01)00069-8

George, J. M., \& Jones, G. R. (2000). The role of time in theory and theory building. Journal of Management, 26, 657-684. doi: 10.1177/014920630002600404

Gino, F. (2015). Understanding ordinary unethical behavior: Why people who value morality act immorally. Current Opinion in Behavioral Sciences, 3, 107-111. doi: 10.1016/j.cobeha.2015.03.001

Griffin, B. J., Moloney, J. M., Green, J. D., Worthington, E. L., Cork, B., Tangney, J. P., Van Tongeren, D. R., Davis, D. E., \& Hook, J. N. (2016). Perpetrators' reactions to perceived interpersonal wrongdoing: The associations of guilt and shame with forgiving, punishing, and excusing oneself. Self and Identity, 15, 650-661. doi:

$10.1080 / 15298868.2016 .1187669$

Holtz, B. C., \& Harold, C. M. (2013). Interpersonal justice and deviance: The moderating effects of interpersonal justice values and justice orientation. Journal of Management, 39, 339365. doi: 10.1177/0149206310390049

Jones, D. A. (2009). Getting even with one's supervisor and one's organization: Relationships among types of injustice, desires for revenge, and counterproductive work behaviors. Journal of Organizational Behavior, 30, 525-542. DOI: 10.1002/job.563 
Kline, R. B. (2011). Principles and practice of structural equation modeling. NY: Guilford.

Lazarus, R. S. (1991). Emotion and adaptation. New York: Oxford University Press.

Lewis, H. B. (1971). Shame and guilt in neurosis. New York: International Universities Press.

Lind, E. A. (2001). Thinking critically about justice judgments. Journal of Vocational Behavior, 58, 220-226. doi: 10.1006/jvbe.2001.1793

Lind, E. A., \& Tyler, T. R. (1988). The social psychology of procedural justice. New York: Plenum

Marjanovic, Z., Struthers, C. W., Cribbie, R., \& Greenglass, E. R. (2014). The conscientious responders scale: A new tool for discriminating between conscientious and random responders. Sage Open, 4, 1-10. doi: 10.1177/2158244014545964

Mitchell, M. S., Baer, M. D., Ambrose, M. L., Folger, R., \& Palmer, N. F. (2018). Cheating under pressure: A self-protection model of workplace cheating behavior. Journal of Applied Psychology, 103, 54-73. doi: 10.1037/ap10000254

Moore, C., Detert, J. R., Treviño, L. K., Baker, V. L., \& Mayer, D. M. (2012). Why employees do bad things: Moral disengagement and unethical organizational behavior. Personnel Psychology, 65, 1-48. doi: 10.1111/j.1744-6570.2011.01237.x

Moore, C., \& Gino, F. (2013). Ethically adrift: How others pull our moral compass from true North, and how we can fix it. Research in Organizational Behavior, 33, 53-77. doi: 10.1016/j.riob.2013.08.001

Moore, C., \& Gino, F. (2015). Approach, ability, aftermath: A psychological process framework of unethical behavior at work. Academy of Management Annals, 9, 235-289. doi: $10.1080 / 19716520.2015 .1011522$

Mosher, D. L., \& White, B. B. (1981). On differentiating shame and shyness. Motivation and 
Emotion, 5, 61-74. doi: 10.1007/BF00993662

Oç, B., Bashshur, M. R., \& Moore, C. (2015). Speaking truth to power: The effect of candid feedback on how individuals with power allocate resources. Journal of Applied Psychology, 100, 450-463. doi: 10.1037/a0038138

Palan, S., \& Schitter, C. (2018). Prolific.ac-A subject pool for online experiments. Journal of Behavioral and Experimental Finance, 17, 22-27. doi: 10.1016/j.jbef.2017.12.004

Peer, E., Brandimarte, L., Samat, S., \& Acquisti, A. (2017). Beyond the Turk: Alternative platforms for crowdsourcing behavioral research. Journal of Experimental Social Psychology, 70, 153-163. doi: 10.1016/j.jesp.2017.01.006

Podsakoff, P. M., MacKenzie, S. B., \& Podsakoff, N. P. (2012). Sources of method bias in social science research and recommendations on how to control it. Annual Review of Psychology, 63, 539-569. doi: 10.1146/annurev-psych-120710-100452

Preacher, K. J., \& Hayes, A. F. (2008). Asymptotic and resampling strategies for assessing and comparing indirect effects in multiple mediator models. Behavior Research Methods, 40, 879-891. doi: 10.3758/BRM.40.3.879

Quick, J. C., Murphy, L. R., Hurrell, J. J., \& Orman, D. (1992). The value of work, the risk of distress, and the power of prevention. In J. C. Quick, L. R. Murphy, \& J. J. Hurrell (Eds.), Stress and well-being at work: Assessment and interventions for occupational mental health (pp. 3-13). Washington, DC: American Psychological Association.

Riketta, M. (2005). Organizational identification: A meta-analysis. Journal of Vocational Behavior, 66, 358-384. doi: 10.1016/j.jvb.2004.05.005

Rodell, J. B., \& Colquitt, J. A. (2009). Looking ahead in times of uncertainty: The role of anticipatory justice in an organizational change context. Journal of Applied Psychology, 
94, 989-1002. doi: 10.1037/a0015351

Ruedy, N. E., Moore, C., Gino, F., \& Schweitzer, M. E. (2013). The cheater's high: The unexpected affective benefits of unethical behavior. Journal of Personality and Social Psychology, 105, 531-548. doi: 10.1037/a0034231

Scherer, K. R., \& Wallbott, H. G. (1994). Evidence for universality and cultural variation of differential emotion response patterning. Journal of Personality and Social Psychology, 66, 310-328. doi: 10.1037/0022-3514.66.2.310

Schminke, M., Ambrose, M. L., \& Noel, T. W. (1997). The effect of ethical frameworks on perceptions of organizational justice. Academy of Management Journal, 40, 1190-1207. doi: $10.2307 / 256932$

Schmitt, M., Gollwitzer, M., Maes, J., \& Arbach, D. (2005). Justice sensitivity. European Journal of Psychological Assessment, 21, 202-211. doi: 10.1027/1015-5759.21.3.202

Shalvi, S., Gino, F., Barkan, R., \& Ayal, S. (2015). Self-serving justifications: Doing wrong and feeling moral. Current Directions in Psychological Science, 24, 125-130. doi: $10.1177 / 0963721414553264$

Shrout, P. E., \& Bolger, N. (2002). Mediation in experimental and nonexperimental studies: New procedures and recommendations. Psychological Methods, 7, 422-445. doi: 10.1037//1082-989X.7.4.422

Shu, L. L., Gino, F., \& Bazerman, M. H. (2011). Dishonest deed, clear conscience: When cheating leads to moral disengagement and motivated forgetting. Personality and Social Psychology Bulletin, 37, 330-349. doi: 10.1177/0146167211398138

Smidts, A., Pruyn, A. T. H., \& Van Riel, C. B. (2001). The impact of employee communication and perceived external prestige on organizational identification. Academy of Management 
Journal, 44, 1051-1062. doi: 10.5465/3069448

Tajfel, H. E. (1978). Differentiation between social groups: Studies in the social psychology of intergroup relations. Oxford, England: Academic Press.

Tajfel, H., \& Turner, J. C. (1985). The social identity theory of intergroup behavior. In S. Worchel \& W. G. Austin (Eds.), Psychology of intergroup relations (2nd ed., pp. 7-24). Chicago: Nelson-Hall.

Tangney, J. P. (1995). Shame and guilt in interpersonal relationships. In J. P. Tangney \& K. W. Fischer (Eds.), Self-conscious emotions: The psychology of shame, guilt, embarrassment, and pride (pp. 114-139). New York: Guilford Press.

Tangney, J. P., Miller, R. S., Flicker, L., \& Barlow, D. H. (1996). Are shame, guilt, and embarrassment distinct emotions? Journal of Personality and Social Psychology, 70, 1256-1269. doi: 10.1037/0022-3514.70.6.1256

Tangney, J. P., Stuewig, J., \& Mashek, D. J. (2007). What's moral about the self-conscious emotions? In J. L. Tracy, R. W. Robins, \& J. P. Tangney (Eds.), The self-conscious emotions: Theory and research (pp. 21-37). New York: Guilford Press.

Törnblom, K. Y., \& Vermunt, R. (1999). An integrative perspective on social justice: Distributive and procedural fairness evaluations of positive and negative outcome allocations. Social Justice Research, 12, 39-64. doi: 10.1023/A:102322630

Tracy, J. L., \& Robins, R. W. (2006). Appraisal antecedents of shame and guilt: Support for a theoretical model. Personality and Social Psychology Bulletin, 32, 1339-1351. doi: $10.1177 / 0146167206290212$

Tracy, J. L., \& Robins, R. W. (2007). The self in self-conscious emotions: A cognitive appraisal approach. In J. L. Tracy, R. W. Robins, \& J. P. Tangney (Eds.), The self-conscious 
emotions: Theory and research (pp. 3-20). New York: Guilford Press.

Tripp, T. M., \& Bies, R. J. (1997). What's good about revenge? The avenger's perspective. Research on Negotiation in Organizations, 6, 145-160.

Turner, J. C. (1982). Towards a cognitive redefinition of the social group. In H. Tajfel (Ed.), Social identity and intergroup relations (pp. 15-40). Cambridge: Cambridge University Press.

Umphress, E. E., \& Bingham, J. B. (2011). When employees do bad things for good reasons: Examining unethical pro-organizational behaviors. Organization Science, 22, 621-640. doi: $10.1287 /$ orsc. 1100.0559

Watson, D., Clark, L. A., \& Tellegen, A. (1988). Development and validation of brief measures of positive and negative affect: The PANAS scales. Journal of Personality and Social Psychology, 54, 1063-1070. doi: 10.1037/0022-3514.54.6.1063

Wenzel, M., Okimoto, T. G., Feather, N. T., \& Platow, M. J. (2008). Retributive and restorative justice. Law and Human Behavior, 32, 375-389. doi: 10.1007/s10979-007-9116-6

Wiesenfeld, B. M., Swann, W. B., Brockner, J., \& Bartel, C. A. (2007). Is more fairness always preferred? Self-esteem moderates reactions to procedural justice. Academy of Management Journal, 50, 1235-1253. doi: 10.2307/AMJ.2007.20159922

Wiltermuth, S. S. (2011). Cheating more when the spoils are split. Organizational Behavior and Human Decision Processes, 115, 157-168. doi: 10.1016/j.obhdp.2010.10.001

Woodyatt, L., \& Wenzel, M. (2014). A needs-based perspective on self-forgiveness: Addressing threat to moral identity as a means of encouraging interpersonal and intrapersonal restoration. Journal of Experimental Social Psychology, 50, 125-135. doi: 10.1016/j.jesp.2013.09.012 


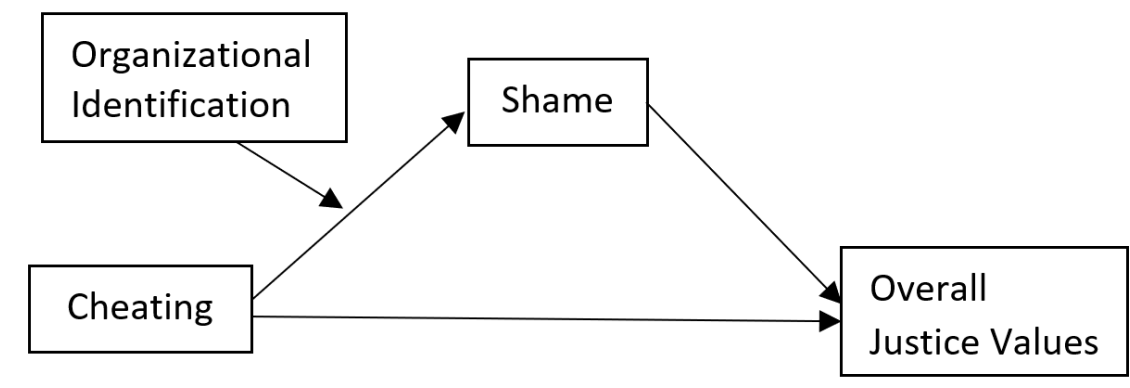

Figure 1. Theoretical Model. 


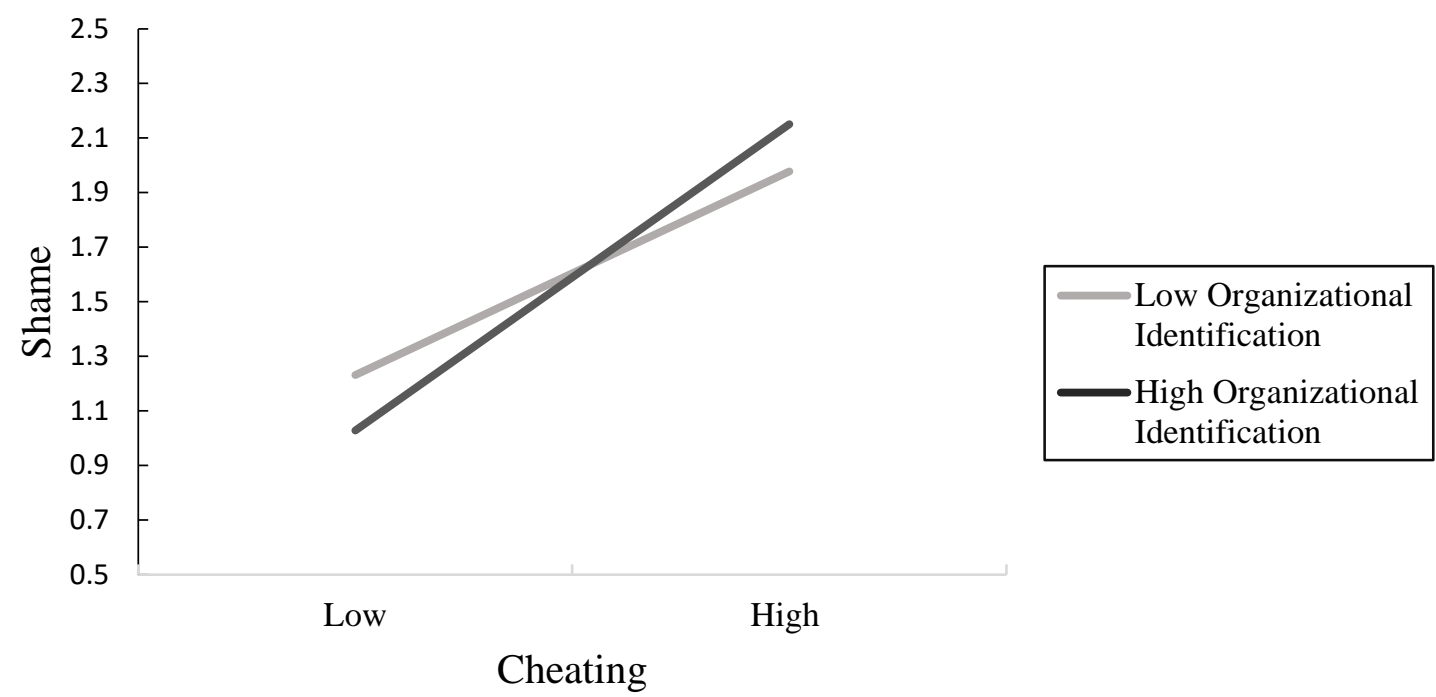

Figure 2. Study 4. Shame as a function of cheating and organizational identification. 


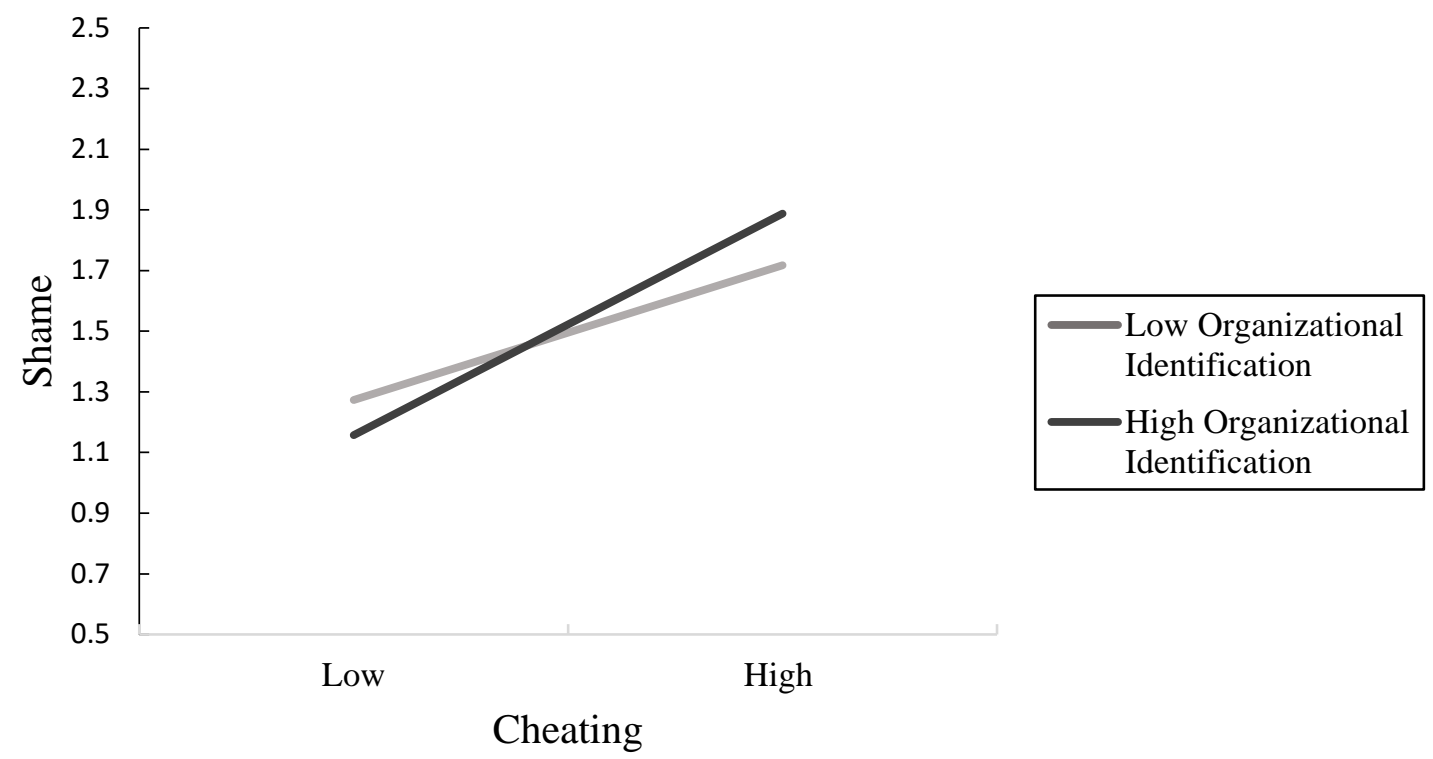

Figure 3. Study 5. Shame as a function of cheating and organizational identification. 
Table 1

Study 1: Means, Standard Deviations, Zero-Order Correlations, and Reliabilities.

\begin{tabular}{lcccccc}
\hline \multicolumn{1}{c}{ Variable } & $M$ & $S D$ & 1 & 2 & 3 & 4 \\
\hline 1. Cheating (T1) & 1.57 & .63 & $(.86)$ & & & \\
2. Overall justice values (T2) & 4.44 & .75 & $-.26 * *$ & $(.96)$ & & \\
3. Cheating (T3) & 1.48 & .65 & $.81 * *$ & $-.19 * *$ & $(.89)$ & \\
4. Overall justice values (T4) & 4.34 & .79 & $-.22 * *$ & $.65 * *$ & $-.22 * *$ & $(.97)$
\end{tabular}

Notes.

$* * p<.01$.

Reliabilities are shown on the diagonal. 
Table 2

Study 1: Structural Equation Modeling Results.

\begin{tabular}{llcc}
\hline Criterion & Predictor & $b$ & $S E$ \\
\hline Overall Justice Values T2 & Cheating T1 & $-.34^{* *}$ & .08 \\
Cheating T3 & Overall Justice Values T2 & .05 & .04 \\
Cheating T3 & Cheating T1 & $.95^{* *}$ & .08 \\
Overall Justice Values T4 & Overall Justice Values T2 & $.72^{* *}$ & .06 \\
Overall Justice Values T4 & Cheating T3 & $-.33^{*}$ & .15 \\
Overall Justice Values T4 & Cheating T1 & .24 & .16 \\
\hline $\begin{array}{l}\text { Notes. } \\
*<<.05 .\end{array}$ & & & \\
$* * p<.01$. & & &
\end{tabular}


Table 3

Study 2: Means, Standard Deviations, Zero-Order Correlations, and Reliabilities.

\begin{tabular}{|c|c|c|c|c|c|c|c|c|c|c|c|}
\hline Variable & $M$ & $S D$ & 1 & 2 & 3 & 4 & $\overline{5}$ & 6 & 7 & 8 & 9 \\
\hline 1. Cheating & .52 & .50 & - & & & & & & & & \\
\hline 2. Shame & 1.59 & .73 & $.15^{*}$ & $(.79)$ & & & & & & & \\
\hline 3. Interpersonal justice values & 4.43 & .62 & $-.19 * *$ & $-.22 * *$ & $(.86)$ & & & & & & \\
\hline 4. Procedural justice values & 4.21 & .69 & $-.15 \dagger$ & $-.13 \dagger$ & $.50 * *$ & $(.90)$ & & & & & \\
\hline 5. Distributive justice values & 4.39 & .59 & $-.18^{*}$ & -.12 & $.51 * *$ & $.65^{* *}$ & $(.89)$ & & & & \\
\hline 6. State moral disengagement & 2.66 & .65 & $.16^{*}$ & $.21 * *$ & $-.15^{*}$ & -.04 & -.08 & $(.69)$ & & & \\
\hline 7. Propensity to morally disengage & 2.58 & 1.06 & $.31 * *$ & .06 & $-.23 * *$ & -.04 & $-.18^{*}$ & $.19 *$ & $(.86)$ & & \\
\hline 8. State negative affect & 2.28 & 1.19 & -.06 & $.47 * *$ & $-.32 * *$ & $-.21 * *$ & $-.20 * *$ & $.15 \dagger$ & $.15 \dagger$ & $(.85)$ & \\
\hline 9. Outcome favorability values & 4.06 & .69 & -.05 & -.04 & $-.30 * *$ & $-.43 * *$ & $-.42 * *$ & .12 & .01 & .02 & $(.92)$ \\
\hline
\end{tabular}


Table 4

Study 3: Means, Standard Deviations, Zero-Order Correlations, and Reliabilities.

\begin{tabular}{|c|c|c|c|c|c|c|c|c|}
\hline Variable & $M$ & $S D$ & 1 & 2 & 3 & 4 & 5 & 6 \\
\hline 1. Cheating & 0.49 & .50 & - & & & & & \\
\hline 2. Shame & 1.45 & .76 & $.11 *$ & $(.85)$ & & & & \\
\hline 3. Guilt & 2.30 & 1.61 & $.39 * *$ & $.37 * *$ & $(.93)$ & & & \\
\hline 4. Overall justice values & 4.17 & .90 & $-.11^{*}$ & $-.11^{*}$ & -.09 & $(.96)$ & & \\
\hline 5. Organizational identification & 3.64 & .96 & $-.13 *$ & $-.15 * *$ & .02 & $.45^{* *}$ & $(.93)$ & \\
\hline 6. Manipulation check & 2.31 & 1.07 & $.75 * *$ & $.19 * *$ & $.44 * *$ & -.08 & $-.14 * *$ & $(.86)$ \\
\hline
\end{tabular}


Table 5

Study 4: Means, Standard Deviations, Zero-Order Correlations, and Reliabilities.

\begin{tabular}{lccccccc}
\hline & Variable & $M$ & $S D$ & 1 & 2 & 3 & 4 \\
\hline 1. Cheating & 1.71 & .87 & $(.84)$ & & & & \\
2. Shame & 1.54 & .92 & $.56 * *$ & $(.92)$ & & \\
3. Guilt & 2.34 & 1.56 & $.52 * *$ & $.59 * *$ & $(.91)$ & \\
4. Overall justice values & 4.33 & .78 & $-.25 * *$ & $-.31 * *$ & $-.18 * *$ & $(.94)$ \\
5. Organizational identification & 3.64 & .92 & $-.11 *$ & -.09 & .01 & $.31 * *$ & $(.92)$ \\
\hline
\end{tabular}

Notes.

$* p<.05$.

$* * p<.01$.

Reliabilities are shown on the diagonal.

Shame was measured on a 5-point scale whereas guilt was measured on a 7-point scale (see Study 4 Measures). 
Table 6

Study 5: Means, Standard Deviations, Zero-Order Correlations, and Reliabilities.

\begin{tabular}{lccccccc}
\hline \multicolumn{1}{c}{ Variable } & $M$ & $S D$ & 1 & 2 & 3 & 4 & 5 \\
\hline 1. Cheating & 1.74 & .69 & $(.86)$ & & & & \\
2. Shame & 1.50 & .81 & $.36^{* *}$ & $(.86)$ & & & \\
3. Guilt & 2.52 & 1.54 & $.38^{* *}$ & $.54^{* *}$ & $(.91)$ & & \\
4. Overall justice values & 4.44 & .68 & $-.19^{*}$ & $-.15^{* *}$ & -.08 & $(.95)$ & \\
5. Organizational identification & 3.56 & .96 & $-.13^{*}$ & -.02 & $.15^{* *}$ & $.16^{* *}$ & $(.92)$ \\
\hline
\end{tabular}

Notes.

$* p<.05$.

$* * p<.01$.

Reliabilities are shown on the diagonal.

Shame was measured on a 5-point scale whereas guilt was measured on a 7-point scale (see Study 5 Measures). 
Table 7

Study 6: Means, Standard Deviations, Zero-Order Correlations, and Reliabilities.

\begin{tabular}{lcrccccc}
\hline \multicolumn{1}{c}{ Variable } & $M$ & $S D$ & 1 & 2 & 3 & 4 & 5 \\
\hline 1. Cheating & 1.33 & .50 & $(.67)$ & & & & \\
2. Shame & 1.30 & .67 & $.25^{* *}$ & $(.78)$ & & & \\
3. Guilt & 2.27 & 1.80 & $.20^{* *}$ & $.33^{* *}$ & $(.95)$ & & \\
4. Overall justice values & 4.41 & .95 & $-.21^{* *}$ & $-.23^{* *}$ & .00 & $(.90)$ & \\
5. Organizational identification & 3.52 & 1.13 & $-.29 * *$ & $-.21^{* *}$ & .03 & $.34 * *$ & $(.94)$ \\
\hline
\end{tabular}

Notes.

** $p<.01$

Reliabilities are shown on the diagonal.

Shame was measured on a 5-point scale whereas guilt was measured on a 7-point scale (see Study 6 Measures). 